E. Pflüger und K, Bohland: Verbesserung der Harnstoff-Analyse etc. $\mathbf{5 7 5}$ geordnet und in den verschiedenen Regionen der $\%$-Gehalte Mittel gezogen. Wer an den Mitteln die von uns aufgestellte Regel zur Berechnung des procentisehen Stickstoffgehaltes aus dem Volum der verbrauchten Quecksilberlösung vergleicht, wird sie bestätigt finden. Zugleich ersieht man wie gross der Beobachtungsfehler eventuell werden kann, was zu wissen ein grosser Vortheil einer Methode ist.

(Physiologisches Laboratorium in Bonn.)

\title{
Verbesserung der Harnstoff-Analyse von Bunsen mit Berücksichtigung der stickstoffhaltigen Extractivstoffe im menschlichen Harne.
}

\section{Von}

\section{E. Pflüger und $\mathbf{K}$. Bohland.}

Viele Hunderte von Stickstoffbestimmungen des Harnes, welche wir in den letzten Jahren nach der von uns ausgearbeiteten Modifieation der Kjedahl'schen Methode ausführten, haben uns iiberzengt, dass diese zwar nicht an Allgemeinheit, aber, wo sie anwendbar ist, an Zuverlässigkeit und Schärfe allen anderen Methoden - die von Dumas nicht ausgenommen - bei Weitem überlegen ist.

Mit keiner anderen als der Kjeldahl'sehen Methode lassen sich ferner in 24 Stunden so viele gute Stickstoff bestimmungen ausführen und dies ist für den Physiologen und Mediciner ein unschätzbarer Vorzug. - Nur aus ganz besonderen Gründen wird man in Zukunft zur Ermittlung des Gesammtstickstoffs im Harne eine andere Methode in Anwendung bringen.

Da nun aber nicht aller Stickstoff im Harnstoff enthalten ist, 
so sind besondere Methoden zu dessen quantitativer Bestimmung nothwendig, welche eine um so grössere Genauigkeit beanspruchen, je weniger sich die in dem Harnstoff entlaltene von der gesammten Stickstoffmenge unterscheidet. Der Beobachtungsfehler darf offenbar diese Differenz nicht erreichen.

Wir setzten uns demgemäss vor, die Methode von Bunsen kritisch zu priffen und eventuell zu verbessern.

Ist es in der That wahr, dass, wie allgemein angenommen wird, die „Extractivstoffe" des Harnes keinen oder doch nur einen unwesentlichen Fehler bei der Bu nsen'schen Methode bedingen?

$\mathrm{Buns}$ en ${ }^{1}$ ) erkannte bereits selbst, dass Harnsäure und Kreatinin beim Erhitzen auf $220-230^{\circ}$ C. Kohlensäure abspalten. Erstere werde, so meint Bunsen, durch seine ammoniakalische Chlorbariumlösung vor der Erhitzung vollständig ausgefällt und letzteres sei in zu geringer Menge vorhanden, um einen wesentlichen Fehler zu bedingen. Beide Behauptungen Bunsens sind nicht ganz unbedenklich. Die quantitative Analyse des Kreatinins ist sogar hente noch, wie Salkowsky nenerdings nachwies, ganz unsicher und ausserdem kommen im Harne für Harnsäure und wohl auch deren Salze unbekannte und gute Lösungsmittel vor. - Von den anderen bekannten etwa in Betracht kommenden Körpern prüfte $B$ unsen Hippursäure und Benzoesäure, welche indessen keine Kohlensäure beim Erhitzen lieferten.

Um sich noch weiter zu überzengen, fällte Bunsen mit basisch essigsaurem Bleioxyd die "Extractivstoffe" aus und fand, dass der Harn nun allerdings weniger Kohlensäure beim Erhitzen lieferte.

Nicht ausgefällter Harn:

Ausgefällter Harn:

$$
2,446
$$$$
2,442
$$

Mittel 2,449 Harnstoff.

2,374 Harnstoff.

Bu n s en hält die Differenz für irrelevant. Sie entspricht indessen einem Beobachtungsfehler von 3,0\% im Stickstoff. - Wir haben ausserdem durch besondere Versuche gefunden, dass von den stickstoff haltigen Körpern, die neben dem Harnstoff im Harn enthalten sind, nur der kleinere Theil durch basisches essigsaures Bleioxyd gefällt wird.

1) Liebig, Ann. 66, 375 . 
Da Bunsen ferner die Frage nur an einem Harne geprüft hat und die Harne unter verschiedenen physiologischen Bedingungen sehr verschiedene Zusammensetzung zeigen, so wäre es immerhin möglich, dass in anderen Fällen die Extractivstoffe einen grösseren nicht mehr zu vernachlässigenden Beobachtungsfebler bedingen.

$\mathrm{Bu}$ sen suchte nun allerdings noch auf anderem Wege den eventuellen Einfluss der „Extractivstoffe“ zu widerlegen.

„Zur Entscheidung der Frage, ob die Gegenwart leicht zersetzbarer thierischer Stoffe die Genauigkeit der Methode beeinträchtigen könnte“, sagt Bu n se n, ,,wurde als Lösungsmittel für den zu bestimmenden Harnstoff der wässerige Auszug eines Gemenges von Mileh, Eiweiss, Blutkuchen, Muskelfaser, Sehnen, Fett, Speichel, Nasensehleim, Harnzucker, Kochsalz, schwefelsaurem Natron und phosphorsaurem Ammoniak benutzt, nachdem die durch alkalische Chlorbariumlösung entstandene Fällung von der klar durelr das Filter gehenden Flïssigkeit getrennt war".

Was die Beweiskraft dieser Versuche einigermaassen beeinträchtigt ist, dass Bunsen nicht einmal so viel Koblensäure wiederfindet als dem zugesetzten Harnstoff entsprach und dass Harn eine Zusammensetzung hat, die in keiner anderen thierischen Flüssigkeit wiederkebrt. Denn die Niere häuft gewisse, in anderen Organen nur in Spuren vorkommende Stoffe im Harne auf, sodass hier Substanzen in grossen Mengen vorkommen können, die in den thierischen Säften in nicht oder kaum nachweisbarer Menge enthalten sind. Man denke nur an den Harnstoff selbst.

Der Weg, den wir betraten, war principiell der von $B$ unsen bereits gewählte, unterschied sich aber darin, dass wir statt mit Bleiessig mit Phosphorwolframsäure und Salzsäure den Harn ausfällten und nach Neutralisation im zugeschmolzenen Rohr 4-5 Stunden auf $220^{\circ}$ bis $230^{\circ} \mathrm{C}$. erhitzten. In einem Parallelversuch wurde derselbe nicht durch Phosphorwolframsäure ausgefällte Harn nach $B$ un sen auf seinen Harnstoffgehalt untersucht. Da wir aber nicht bloss die durch die Erhitzung entstandene Kohlensäure, sondern auch das Ammoniak bestimmen wollten, führten wir die Analysen in der von Salkowsky vorgeschriebenen Weise aus und benutzten nicht eine dureh Zusatz von Ammoniak, sondern von Natron alkalisch gemachte Chlorbaryumlösung. Jedesmal bestimmten wir auch den Gesammtstickstoff nach Kjeldahl. 


\section{Vorversuch $\theta^{1}$ ).}

Unsere erste Aufgabe war die Ermittelung, ob bei den beabsichtigten Fällungen der Harnstoff selbst nicht mitgefällt werde.

\section{Versuch I.}

1. Je $5 \mathrm{ccm}$ Harnstofflösung wurden nach unserer Modification der Kjeldahl'schen Methode auf ihren Stickstoffgehalt untersucht. Vorlage am Destillationsapparat $=40 \mathrm{ccm} 1 / 10 \mathrm{SO}_{4} \mathrm{H}_{2}$. - Gebraucht in 2 Versuchen $3,03 \mathrm{ccm}$ und $3,05 \mathrm{ccm} 1 / 10$ Hyporsulfitlösung,

entsprechend: 0,05191 und $0,05188 \mathrm{gr}$ Stickstoff

Mittel: $0,05189 \mathrm{gr}$ Stickstoff $=5 \mathrm{~cm}$ Lösung.

2.

$25 \mathrm{ccm}$ dieser Harnstofflösung,

2,5 ccm Salzsäure (1,124 sp. Gew.),

+25 ccm Phosphorwolframsäure

wurden über Nacht in wohl verschlossenem Kölbchen stehen gelassen. Es tritt keine Trübung ein. Die Flüssigkeit wird mit lufttrocknem Kalkpulver $\left(\mathrm{Ca}(\mathrm{OH})_{2}\right)$ bis zur alkalischen Reaction zerrieben, und in je $5 \mathrm{ccm}$ des Filtrates nach KjeldahI der Stickstoff bestimmt.

Destillationsvorlage $20 \mathrm{~cm} \quad 1 / 10 \quad \mathrm{SO}_{4} \mathrm{H}_{2}$. Gebraucht $1 / 10$ Hyposulfit: $2,16 \mathrm{ccm}$ und $2,15 \mathrm{~cm}$, entsprechend $0,02505 \mathrm{gr}$ und $0,02506 \mathrm{gr}$ Stickstoff.

Mittel: $0,025055 \mathrm{gr}$ Stickstoff.

Die uncorrigirte Rechnung ergibt, dass die theoretische Zahl sein sollte: $0,02471 \mathrm{gr}$ Stickstoff.

Um die Correctur auszuführen, ist das Volum des Niederschlags sowie eine etwaige Vergrösserung des Flüssigkeitsvolumens (durch Wasserbildung) festzustellen.

10 com obiger Mischung von Harnstoff, Salzsäure und Phosphorwolframsäure,

$2 \mathrm{ccm}$ verdünnte Natronlauge (zum Neutralisiren der Salzsäure, gibt mit Wasser keine Volumänderung),

$150,24 \mathrm{ccm}$ Kalkwasser,

$37,86 \mathrm{ccm} \mathrm{Kalkwasser,}$

$200,10 \mathrm{ccm}$.

Der Inhalt des Kolbens ergab sich genau geaicht zu 200,1 ccm. Es fand also bei der Neutralisation der Süure keine Volumänderung statz.

Nun wurde der Niederschlag abfiltrirt, das Filter auf einem ebenen Bausch Fliesspapier ausgebreitet, ein zweites Filter auf den Niederschlag gelegt und in die Presse gebracht. Dann legt man die Filter einige Zeit in absoluten Alkohol. Bald hebt sich leicht das eine Papier ab rom Niederschlage und dieser lässt sich vollständig auf ein Uhrglas schütten, auf dem man ihn schnell völlig trocknet. Nun füllt man ein calibrirtes Rohr mit

1) In dieser Abhandlung ist überall $1 \mathrm{ccm} \quad 1 / 10 \quad \mathrm{SO}_{4} \mathrm{H}_{2}$ aequivalent $1 \mathrm{ccm} 1 / 10$ Hyposulfitlösung und entspricht 1,404 mgr Stickstoff. 
Petroleumäther, liest $a b$, füllt den Niederschlag ein, aus dem alle Luftbläschen rasch entweichen, und liest wieder ab, um wie viel sich das Niveau des Petroleumäthers gehoben hat. Unter Benutzung eines trocknen Trichters mit kurzem weiten Rohr lässt sich die Ueberführung des Pulvers, wenn es nur recht trucken ist, ohne Verlust vollziehen. Im Maassrohr muss so viel Petroleumäther sein, als die Umstände erlauben.

Es ergab sich so das Volum des Niederschlags für $10 \mathrm{ccm}$ Mischung $=0,2 \mathrm{ccm}$, für $52,5 \mathrm{ccm}$ Mischung, welche wir ja oben angewandt batten, beträgt der Niederschlag $1,05 \mathrm{ccm}$.

Die Correctur ergibt also: $(52,5-1,05): 25=5: \mathrm{x} . \mathrm{x}=2,4295 \mathrm{ccm}$ Harnstoffiösung in $5 \mathrm{ccm}$ alkalischem Filtrat, $5 \mathrm{ccm}$ Filtrat also $=0,02521 \mathrm{gr}$ Stickstoff.

$$
\begin{gathered}
\text { Also gefunden: } \\
0,02506
\end{gathered}
$$

\section{Berechnet: \\ 0,02521 corrigirt, 0,02471 nicht corrigirt.}

Es wird demnach kein Harnstoff durch Phosphorwolframsäure, Salzsäure und nachherige Neutralisation mit Kalk gefällt.

Obige Correctionsrechnung lehrt zugleich, dass die Unterlassung der Correctur nur einen Fehler von 1,4\% im Stickstoff zar Folge haben würde.

\section{Versuch II.}

Aus einem später erhellenden Grunde stellten wir noch solche Versuche an, bei denen in $100 \mathrm{~cm}$ Harmstofflösung $2 \mathrm{gr}$ Chlornatrium enthalten waren.

1. Gesammtstickstoff nach Kjeldahl in $5 \mathrm{~cm}$ Lösung. Vorlage $40 \mathrm{ccm}$ $1 / 10 \mathrm{SO}_{4} \mathrm{H}_{2} .1 / 10$ Hypersulfitlösung gebraucht $6,96 \mathrm{ccm}$ und $7,0 \mathrm{ccm}$. entsprechend: $0,04639 \mathrm{gr}$ und $0,04633 \mathrm{gr}$ Stickstoff.

Mittel: 0,04636 gr Stickstoff.

2. $25 \mathrm{ccm}$ der in II. 1. analysirten Chlornatrium-Harnstofflösung $+2,5 \mathrm{ccm}$ Salzsäure $+25 \mathrm{ccm}$ Phosphorwolframsäure werden, nachdem sie über Nacht gestanden, mit $\mathrm{Kalkpulver}\left(\mathrm{Ca}(\mathrm{OH})_{2}\right)$ neutralisirt und je $5 \mathrm{ccm}$ des Filtrates nach $\mathrm{KjeldahI}$ analysirt. Fórlage $20 \mathrm{ccm} 1 / 10 \mathrm{SO}_{4} \mathrm{H}_{2}$, gebraucht $1 / 10$ Hyposulfitlösung $3,85 \mathrm{ccm}$ und $3,80 \mathrm{ccm}$

entsprechend: $0,02267 \mathrm{gr}$ und $0,02275 \mathrm{gr}$ Stickstoff. Mittel: 0,02271 gr Stickstoff.

Also Gefunden: wirklicher Werth

$$
\left.\begin{array}{rl}
5 \mathrm{ccm} & =0,04761 \mathrm{gr} \text { Stickstoff (uncorrigirt) } \\
\# & =0,04672 \mathrm{gr} \quad \# \quad \text { (corrigirt) }
\end{array}\right\} 0,04636 \mathrm{gr} \text { Stickstoff. }
$$

Zur Correctur ist $\mathrm{zu}$ bemerken:

In ein $200 \mathrm{ccm}$ Kölbchen wurden eingefüllt bis zur Marke:

$10 \mathrm{ccm}$ obiger Harnstoff-Phosphorwolframsäure-Mischung,

2 "Natronlauge,

$150,24 \mathrm{ccm}$ Kalkwasser,

37,86 "Kalkwasser.

$200,10 \mathrm{ccm}$. 
Der Inhalt des Fläschchens war aber aber beim Aichen $=200,1 \mathrm{ccm}$ gefunden worden.

Beim Neutralisiren mit $\mathrm{Ca}(\mathrm{OH})_{2}$ erwies sich also die Expansion gleich Null; das Volum des Niederschlags betrug $1,05 \mathrm{ccm}$ für $52,5 \mathrm{ccm}$ Mischung.

Es kann also als sicher gelten, dass bei den beschriebenen Operationen kein Harnstoff mitgefällt wird.

\section{Versuch III.}

Warum wir die saure Harnstoffmischung nicht mit $\mathrm{Ba}(\mathrm{OH})_{2}$ neutralisirten, ergibt sich aus folgenden Versuchen:

\section{Versuch A.}

$25 \mathrm{ccm}$ Harnstofflösung (die gemäss Versuch 1 enthielten $0,25960 \mathrm{gr}$ Stickstoff) $+2,5 \mathrm{ccm}$ Salzsäure $+12,5 \mathrm{ccm}$ Phosphorwolframsäure werden mit Barytpulver $\left(\mathrm{Ba}\left(\mathrm{OH}_{2}\right)\right)$ neutralisirt. Nach $\mathrm{Kjeldahl}$ je $5 \mathrm{ccm}$ des Filtrats analysirt. Vorlage $26 \mathrm{ccm} 1 / 10 \mathrm{SO}_{4} \mathrm{H}_{2}$. Gebraucht $1 / 10$ Hyposulfitlösung $3,85 \mathrm{ccm}$ : $0,03110 \mathrm{gr}$ Stickstoff, also $5 \mathrm{ccm}=0,04976 \mathrm{gr}$ Stickstoff (uncorrigirt).

Wegen Ermittlung der Correctur wurde festgestellt:

$25 \mathrm{ccm}$ Harnstofflösung,

$2,5 \mathrm{ccm}$ Salzsäure,

$12,5 \mathrm{ccm}$ Phosphorwolframsäure.

$40,10 \mathrm{ccm}$ Mischung

ergab bei Nentralisation mit Barytwasser eine Expansion von $0,36 \mathrm{ccm}$ und einen Niederschlag von $0,435 \mathrm{ccm}$ Volum. Das macht auf die $40 \mathrm{ccm}$ Mischung eine Contraction des Flüssigkeitsvolumens von $0,075 \mathrm{ccm}$, die vernachlässigt werden darf.

Also:

$$
\begin{array}{cc}
\text { Berechnet: } & \text { Gefunden: } \\
0,0519 \mathrm{gr} \text { Stickstoff, } & 0,04976,
\end{array}
$$

also über $4 \%$ des vorhandenen Harnstoffs durch den Barytniederschlag mitgefällt.

\section{Versuch B.}

$25 \mathrm{ccm}$ Harnstofflösung (0,2596 gr Stickstoff enthaltend), $0,25 \mathrm{~cm}$ Salzsäure $50,0 \mathrm{ccm}$ Phosphorwolframsäure,

$50,25 \mathrm{ccm}$ Mischung

mit Barytwasser neutralisirt. - $50 \mathrm{ccm}$ dieser Mischung mit Barytwasser neutralisirt gaben eine Expansion von $0,4 \mathrm{~cm}$ und einen Niederschlag von $0,87 \mathrm{~cm}$ Volum. Die Flüssigkeit erleidet also eine Contraction von $0,47 \mathrm{ccm}$.

$5 \mathrm{ccm}$ Filtrat müssten also enthalten: $0,02608 \mathrm{gr}$ Stickstoff.

Je $5 \mathrm{ccm}$ nach $\mathrm{Kjeldahl}$ analysirt: Vorlage $20 \mathrm{com} 1 / 10 \mathrm{SO}_{4} \mathrm{H}_{2}$.

Gebraucht $1 / 10$ Hyposulfitlösung $1,9 \mathrm{~cm}$ und 2,0 ccm, 
entsprechend: $0,02541 \mathrm{gr}$ und $0,02527 \mathrm{gr}$ Stickstofi;

Mittel: $0,02534 \mathrm{gr}$ Stickstoff.

Also:

Berechnet:

Gefunden:

$0,02608 \mathrm{gr}$ Stickstoff.

$0,02534 \mathrm{gr}$ Stickstoff.

Es sind also 2,9\% des vorhandenen Stickstoffs resp. Harnstoffs durch den Barytniederschlag mit eingeschlossen worden.

Da der Harnstoff mit Chloriden sich verbindet und Barytniederschläge Chloride gern einschliessen, so glaubten wir auch bei der Fällung mit Kalk dem Chlor Beachtung schenken zu müssen, wie der Leser sich erinnert.

Unsere fermere Aufgabe bestand darin, Harnstofflösungen nach Bunsen zu analysiren, indem wir sonst genau so verfuhren, wie wir es mit dem wirklichen Harne thun wollten.

\section{Versuch IV.}

Analyse einer bekanrıten Harnstofflösung nach Bunsen.

1. 5,014 kleine $\mathrm{ccm}=5$ gewöhnliche $\mathrm{ccm}$ einer $1 \%$ igen Harnstofflösung mussten enthalten: $0,02344 \mathrm{gr}$ Stickstoff.

Die Bestimmung nach Kjeldahl ergab: 0,02350 gr Stickstoff;

Vorlage war $21 \mathrm{~cm} 1 / 10 \quad \mathrm{SO}_{4} \mathrm{H}_{2}$.

Gebraucht wurde in 2 Bestimmungen $1 / 10$ Hypersulfitlösung $4,26 \mathrm{ccm}$.

2. Diese Harnstofflösung wurde mit gleichem Volum durch Natronhydrat alkalisirter $\mathrm{BaCl}_{2}$-lösung ${ }^{1}$ ) versetzt, je $15 \mathrm{~cm}$ der Mischung eingeschmolzen und 4 Stunden anf 220 bis $230^{\circ} \mathrm{C}$. erhitzt.

a) Rohr I dient zur Bestimmung des entstandenen Ammoniaks, das abdestillirt wird. Vorlage $30 \mathrm{ccm} 1 / 10 \mathrm{SO}_{4} \mathrm{H}_{2}$.

Gebraucht 1/10 Hyposulfitlösung 5,03 ccm, also: $0,03506 \mathrm{gr}$ Stickstoff gefunden.

Theorie: $0,03515 \mathrm{gr}$ Stickstoff.

b) Rohr II dient zur Bestimmung der entstandenen Kohlensäure.

Der Recipient der Pflüger'schen evacuirten Blutgaspumpe enthält eine geeignete Menge von Citronensäurelösung. Am tiefsten Theil des Recipienten ist ein mit Hahn versehenes Rohr angebracht, über welches ein dickwandiger Gummischlauch gezogen ist. Nachdem das Spitzchen des eingeschmolzenen Rohres abgesprengt, schiebt man den conischen Theil desselben leicht in den Gummischlauch und bindet mit Schnur hermetisch zu. Der Recipient ist durch Schliff so mit den Trockenräumen verbunden, dass durch eine Drehung der tiefste Theil desselben zum höchsten gemacht werden kann. Es gelingt deshalb leicht, nicht bloss das Rohr in den Recipienten zu ent-

1) Alle hier gebrauchten alkalischen Chlorbariumlösungen sind nach Salkowsky's Vorschrift dargestellt. 
leeren, sondern es auch unter Erwärmung mit Citronensäure auszuspülen. Mit grosser Sorgfalt muss darauf geachtet werden, ob die im Rohr enthaitenen Partikelchen bei Umspülung der Säure und besonders bei Erhitzung mit der Flamme noch Glasbläschen entwickeln. Die entwickelte Kohlensäure wird in bekannter Weise in ein Absorptionsrohr gepumpt und mit Kalilauge von 1,36 spec. Gew. absorbirt. $\mathrm{Da}$ das Gas trocken in das Absorptionsrohr gelangt, in welches man den vorschriftsmässigen Tropfen Wasser gebracht hat, so dauert es immer eine Reihe von Stunden, bis das Gas gesättigt ist. Ganz Analoges gilt nach Einführung der Kalilauge, die langsam die Wassertension herabsetzt. Man hat also durch nach längeren Zeiträumen (Stunden) wiederholte Ablesungen sich von der Constanz der Niveau's zu überzeugen. Diese Methode ist zwar mühsam, aber höchst genau und zuverlässig.

Die Analyse ${ }^{1}$ ) der Kohlensäure aus Rohr II:

$$
\begin{aligned}
& \text { Hgu }=67,02 \\
& \text { Hgo }=39,31 \quad \text { Kaliber }\left\{\begin{array}{l}
39,15 \mathrm{~cm}=84 \mathrm{~cm} \quad \mathrm{~T}=7,4^{0} \mathrm{C} . \\
1 \mathrm{~cm}=2,22 \mathrm{~cm} \quad \mathrm{Ba}=749,2 \mathrm{~mm} . \\
\mathrm{V}=84,58 \mathrm{~cm} ; \mathrm{P}=463,81 \mathrm{~mm}
\end{array} \text { Reducirtes Gesammtgas }=50,252 \mathrm{ccm} .\right. \\
& \text { Nach der Absorption der Kohlensäure: }
\end{aligned}
$$

$$
\begin{aligned}
& \begin{aligned}
\mathrm{Hgu}=67,10 \\
\mathrm{Hgo}=25,15 \\
\mathrm{KOH}=23,70
\end{aligned} \quad \text { Kaliber }\left\{\begin{array}{l}
23,85 \mathrm{~cm}=51 \mathrm{ccm} \quad \mathrm{T}=6,5^{\circ} \mathrm{C} . \\
1 \mathrm{~cm}=2,14 \mathrm{~cm} \quad \mathrm{Ba}=767,6 \mathrm{~mm} .
\end{array}\right. \\
& \mathrm{V}=50,68 \mathrm{ccm} ; \mathrm{P}=343,22 \mathrm{~mm} \text {. } \\
& \text { Reducirtes restirendes Gas }=22,355 \mathrm{ccm} \text {. }
\end{aligned}
$$

Folglich $27,897 \mathrm{ccm} \mathrm{CO}_{2}=54,862 \mathrm{mgr} \mathrm{CO}_{2}: 74,82 \mathrm{mgr} \stackrel{+}{\mathrm{U}}=0,03491 \mathrm{gr}$ Stickstoff.

Also:

Berechnet: $\quad$ Gefunden aus

$\begin{array}{ccc} & \text { Ammoniak: } & \text { Kohlensäure: } \\ 0,03510 \mathrm{gr} \text { Stickstoff. } & 0,03506 \mathrm{gr} \text { Stickstoff. } & 0,03491 \mathrm{gr} \text { Stickstoff. }\end{array}$

\section{Versuch V.}

Analyse einer bekannten Harnstofflösung nach Bunsen, wobei aber dieselben fällenden Reagentien zugesetztwerden, welche auch beim Harne Anwendung finden sollen.

$40 \mathrm{ccm}$ der in Versuch IV verwandten Harnstofflösung, 4 "Salzsäure,

20 "Phosphorwolframsäure,

$64 \mathrm{ccm}$ Mischung.

1) Die Abkürzungen bei den Analysen bedeuten:

$\mathrm{Hgu}=$ die Ablesung des Quecksilberniveaus der Wanne an dem untern Theil des Absorptionsrohrs,

Hgo = die Ablesung des Quecksilber-Meniscus am Absorptionsrohr, $\mathrm{KOH}=$ die Ablesung des Kalilange-Meniscus am Absorptionsrohr. 
Steht über Nacht, bleibt klar; Neutralisation mit Kalkpulver $\left(\mathrm{Ca}(\mathrm{OH})_{2}\right)$ und Filtration. Das Volum des Niederschlags $=1,03 \mathrm{ccm}$.

Ferner in ein $200 \mathrm{ccm}$ Kölbchen gemessen:

$10 \mathrm{ccm}$ Harnstoff-Phosphorwolframsäure-Salzsäuremischung,

$2 \mathrm{ccm}$ verdünnte Natronlauge,

$150,24 \mathrm{ccm}$ Kalkwasser,

$37,86 \mathrm{~cm}$ Kalkwasser,

$200,10 \mathrm{ccm}$ Mischung.

200, I ccm war aber der geaichte Inhalt des Fläschchens. Durch Neutralisation der sauren Mischung findet also eine Contraction der Fliissigkeit statt. Das alkalische Filtrat wird nun mit gleichem Volum alkalischer $\mathrm{BaCl}_{2}$ lösung versetzt und bleibt völlig klar. Es ergibt sich also, dass $15 \mathrm{ccm}$ eingeschmolzene Mischung, wenn man auf Grund obiger Versuche die Contraction der Flüssigkeit berechnet, enthalten müssen:

$$
0,02239 \mathrm{gr} \text { Stickstoff. }
$$

Die Bunsen'sche Analyse ergibt nun:

Rohr I. Ammoniakbestimmung.

Vorlage: $17 \mathrm{ccm} 1 / 10 \mathrm{SO}_{4} \mathrm{H}_{2}$. Gebraucht $1 / 10$ Hyposulfitlösung: $4,5 \mathrm{ccm}$, entsprechend: $0,01755 \mathrm{gr}$ Stickstoff.

Da aber für die Ammoniakbestimmung nur $12 \mathrm{~cm}$ Mischung eingeschmolzen wurden, so folgt für $15 \mathrm{ccm}$

$$
0,02194 \mathrm{gr} \text { Stickstoff. }
$$

Rohr II. Kohlensäurebestimmung:

$$
\begin{aligned}
& \begin{array}{l}
\text { Hgu }=67,07 \\
\text { Hgo }=35,50
\end{array} \quad \text { Kaliber }\left\{\begin{array}{l}
35,00 \mathrm{~cm}=75 \mathrm{~cm} \quad \mathrm{~T}=8,0^{\circ} \mathrm{C} . \\
1 \mathrm{~cm}=2,14 \mathrm{ccm} \quad \mathrm{Ba}=765,0 \mathrm{~mm} .
\end{array}\right. \\
& \mathrm{V}=76,28 \mathrm{~cm} ; \mathrm{P}=440,67 \mathrm{~mm} \text {. } \\
& \text { Reducirtes Gesammtgas }=42,97 \mathrm{ccm} \text {. }
\end{aligned}
$$

Nach Absorption der Kohlensäure:

$$
\begin{aligned}
& \begin{array}{l}
\text { Hgu }=66,55 \\
\text { Hgo }=27,35 \\
\mathrm{KOH}=24,80
\end{array} \text { Kaliber }\left\{\begin{array}{l}
25,25 \mathrm{~cm}=54 \mathrm{ccm} \quad \mathrm{T}=5,9^{\circ} \mathrm{C} . \\
1 \mathrm{~cm}=2,14 \mathrm{com} \quad \mathrm{Ba}=764,6 \mathrm{~mm} .
\end{array}\right. \\
& \mathrm{V}=53,04 \mathrm{~cm} ; \mathrm{P}=366,75 \mathrm{~mm} \text {. } \\
& \text { Reducirtes restirendes Gas }=25,06 \mathrm{ccm} \text {, } \\
& 0,02241 \mathrm{gr} \text { Stickstoff. }
\end{aligned}
$$

Also :

Berechnet: Gefunden nach Bunsen aus

$$
\text { Ammoniak: Kohlensäure: }
$$

$0,02239 \mathrm{gr}$ Stickstoff. $\quad 0,02194 \mathrm{gr}$ Stickstoff. $\quad 0,02241 \mathrm{gr}$ Stickstoff. 


\section{Versuch VI.}

Wiederholung des blinden Versuchs V.

a) 5 com Harnstofflösung nach Kjeldahl auf den Stick. stoffgehalt untersucht; mit $40 \mathrm{ccm}$ rauchender Schwefelsäure gekocht.

Vorlage $40 \mathrm{ccm} 1 / 10 \mathrm{SO}_{4} \mathrm{H}_{2}$. Gebraucht $1 / 10$ Hyposulfitlösung $6,13 \mathrm{ccm}$ und $6,10 \mathrm{ccm}$.

Mittel: $6,115 \mathrm{cem}: 0,04757 \mathrm{gr}$ Stickstoff, also: 2,039\% Harnstoff resp. 0,952\% Stickstoff.

b) Harnstoffanalyse nach Bunsen.

$50 \mathrm{ccm}$ Harnstofflösung $(0,952 \% \mathrm{~N}$ oder $2,039 \% \stackrel{+}{\mathrm{U}})$,

5 n Salzsäure,

25 „Phosphorwolframsäure,

$80 \mathrm{ccm}$ Mischung (bleibt klar über Nacht).

Mit Kalkpulver $\left(\mathrm{Ca}(\mathrm{OH})_{2}\right)$ nentralisirt; vom Filtrat $45 \mathrm{ccm}$ mit $45 \mathrm{ccm}$ $\mathrm{BaCl}_{2}$-lösung gemischt; je $15 \mathrm{ccm}$ eingeschmolzen. Volum des Kalkniederschlags $=1,05 \mathrm{ccm}$. Also enthalten $15 \mathrm{ccm}$ eingeschmolzene Mischung: $4,75 \mathrm{ccm}$ Harnstofflösung $=0,04519 \mathrm{gr}$ Stickstoff.

c) Ammoniakbestimmung aus dem eingeschmolzenen Rohr I.

Vorlage $40 \mathrm{ccm} \mathrm{1/10} \mathrm{SO}_{4} \mathrm{H}_{2} ;$ Gebraucht 1/10 Hypersulfitlösung 8,03 ccm, entsprechend: $0,04489 \mathrm{gr}$ Stickstoff.

d) Kohlensäurebestimmung. Eingeschmolzenes Rohr II.

$$
\begin{aligned}
& \mathrm{Hgu}=64,27 \text { Kaliber }\left\{40,95 \mathrm{~cm}=87 \mathrm{~cm} \quad \mathrm{~T}=16^{\circ} \mathrm{C} .\right. \\
& \text { Hgo }=41,59 \text { Kaliber }\{1 \mathrm{~cm}=2,206 \mathrm{ccm} \quad \mathrm{Ba}=758,5 \mathrm{~mm} \text {. } \\
& \mathrm{V}=88,633 \mathrm{~cm} ; \mathrm{P}=516,98 \mathrm{~mm} \text {. } \\
& \text { Reducirtes Gesammtgas }=56,96 \mathrm{~cm} \text {. }
\end{aligned}
$$

Nach Absorption der Kohlensäure:

$$
\begin{aligned}
& \begin{array}{l}
\mathrm{Hgu}=64,52 \\
\mathrm{Hgo}=24,19 \\
\mathrm{KOH}=22,72
\end{array} \quad \text { Kaliber }\left\{\begin{array}{l}
22,70 \mathrm{~cm}=48 \mathrm{~cm} \quad \mathrm{~T}=15,6^{\circ} \mathrm{C} . \\
1 \mathrm{~cm}=2,13 \mathrm{~cm} \quad \mathrm{Ba}=760,5 \mathrm{~mm} .
\end{array}\right. \\
& \mathrm{V}=48,043 \mathrm{ccm} ; \mathrm{P}=349,24 \mathrm{~mm} \text {. } \\
& \text { Reducirtes restirendes Gas }=20,885 \mathrm{ccm} \text {. }
\end{aligned}
$$

Also :

$$
\begin{gathered}
36,075 \mathrm{~cm} \mathrm{CO} \mathrm{CO}_{2}=70,945 \mathrm{mgr} \mathrm{CO}_{2}=96,75 \mathrm{mgr} \stackrel{+}{\mathrm{U}} \\
=0,04514 \mathrm{gr} \text { Stickstoff. }
\end{gathered}
$$

Also:

Berechnet: Nach Bunsengefunden:

aus Ammoniak berechnet: aus Kohlensäure berechnet:

$0,04519 \mathrm{gr}$ Stickstoff $\quad 0,04489 \mathrm{gr}$ Stickstoff $\quad 0,04514 \mathrm{gr}$ Stickstoff. 


\section{Versuch VII.}

Aus einem später einleuchtenden Grunde wiederholten wir Versuch VI mit der Modification, dass wir die Harnstofflösung mit Phenol im zugeschmolzenen Rohr erhitzten.

a) $50 \mathrm{ccm}$ Harnstofflösung $(0,952 \%$ Stickstoff resp. $2,039 \% \stackrel{+}{\mathbf{U}})$ $5 \mathrm{ccm}$ Salzsäure, 25 ccm Phosphorwolframsäure,

$80 \mathrm{ccm}$ Mischung.

Mit Kalkpulver neutralisirt; $45 \mathrm{ccm}$ Filtrat $+45 \mathrm{~cm}$ alkalische $\mathrm{BaCl}_{2}$ lösung $+2 \mathrm{gr}$ Phenol $=92,04 \mathrm{ccm}$. Denn $98,06 \mathrm{ccm}$ Wasser $+2 \mathrm{gr}$ von diesem Phenol $=100,1 \mathrm{~cm}$ Lösung. Demnach $15 \mathrm{ccm}$ eingeschmolzene Lösung $=4,645 \mathrm{ccm}$ Harnstofflösung von $0,952 \%$ Stickstoff; also $=0,04412 \mathrm{gx}$ Stickstoff.

b) Ammoniakbestimmung. Rohr I.

Vorlage $40 \mathrm{ccm} 1 / 10 \mathrm{SO}_{4} \mathrm{H}_{2} ;$ Gebraucht $1 / 10$ Hyposulfitlösung $8,4 \mathrm{~cm}$, entsprechend: $0,04437 \mathrm{gr}$ Stickstoff.

c) Kohlensäurebestimmung. Rohr II.

$$
\begin{gathered}
\mathrm{Hgu}=65,15 \\
\mathrm{Hgo}_{\mathrm{g}}=39,84 \quad \text { Kaliber }\left\{\begin{array}{l}
39,15 \mathrm{~cm}=84 \mathrm{~cm} \\
1 \mathrm{~cm}=2,22 \mathrm{~cm}
\end{array} \quad \mathrm{~T}=16,0^{0} \mathrm{C} .\right. \\
\mathrm{V}=85,75 \mathrm{~cm} ; \mathrm{P}=458,5^{0} \mathrm{~mm} . \\
\text { Reducirtes Gesammtgas }=52,28 \mathrm{ccm} .
\end{gathered}
$$

Nach Absorption der Kohlensänre:

$$
\begin{gathered}
\text { Hgu }=65,40 \\
\text { Hgo }=21,60 \text { Kaliber }\left\{\begin{array}{l}
19,64 \mathrm{~cm}=42 \mathrm{~cm} \quad \mathrm{~T}=16,0^{\circ} \mathrm{C} . \\
1 \mathrm{~cm}=2,13 \mathrm{ccm} \quad \mathrm{Ba}=760,5 \mathrm{~mm} .
\end{array}\right. \\
\mathrm{KOH}=20,10 \\
\mathrm{~V}=42,98 \mathrm{ccm} ; \mathrm{P}=314,42 \mathrm{~mm} . \\
\text { Reducirtes restirendes Gas }=16,80 \mathrm{~cm} .
\end{gathered}
$$

Folglich: $35,48 \mathrm{ccm} \mathrm{CO} \mathrm{CO}_{2}=69,775 \mathrm{mgr} \mathrm{CO}_{2}=95,15 \mathrm{mgr} \stackrel{+}{\mathrm{U}}$

$$
=0,04440 \mathrm{gr} \text { Stickstoff. }
$$

Also:

Berechnet:

Gefunden nach Bunsen:

$\begin{array}{lcc} & \text { aus Ammoniak } & \text { aus Kohlensäure } \\ 0,04412 \mathrm{gr} \text { Stickstoff } & 0,04437 \mathrm{gr} \text { Stickstoff } & 0,0440 \mathrm{gr} \text { Stickstoff. }\end{array}$




\title{
II. Analysen des mensehlichen normalen Harnes nach Bunsen.
}

\author{
Versuchsserie $\mathrm{I}$.
}

\section{Harn III.}

I. Bestimmung des Gesammtstickstoffs nach Kjeldahl.

$75 \mathrm{ccm}$ Harn mit $40 \mathrm{ccm}$ rauchender Schwefelsäure 10 Stunden gekocht. Destillationsvorlage: $29 \mathrm{ccm} 1 / 10$ Schwefelsäure.

Gebraucht 1/10 Hyposulfitlösung 8,11 cem und 8,00 ccm, entsprechend: $0,02933 \mathrm{gr}$ und $0,02948 \mathrm{gr}$ Stickstoff;

Mittel: $0,02941 \mathrm{gr}$ Stickstoff.

Harn enthält also $0,588 \%$ Stickstoff in toto.

II. Bestimmung des Harnstoffs nach Bunsen in dem nicht seiner „Extractirstoffe" beraubten Harne.

$70 \mathrm{ccm}$ Harn mit $30 \mathrm{ccm}$ Wasser verdünnt. $50 \mathrm{ccm}$ dieser Mischung mit $50 \mathrm{ccm}$ durch Natronhydrat alkalisirter $\mathrm{BaCl}_{2}-\mathrm{Lösung}$ versetzt, je $15 \mathrm{ccm}$ vom Filtrat $=5,25 \mathrm{ccm}$ Harn eingeschmolzen und 4 Stunden bei $220^{\circ}$ bis $230^{\circ}$ C. erhitzt.

a) Rohr I. Bestimmung des entstandenen Ammoniaks durch Destillation mit $30 \mathrm{ccm}$ Natronlauge von 1,25 spec. Gew., dem noch circa $500 \mathrm{ccm}$ Wasser zugefügt wurden. Vorlage $30 \mathrm{ccm} 1 / 10 \mathrm{SO}_{4} \mathrm{H}_{2}$.

Gebraucht 1/10 Hyposulfitlösung $9,17 \mathrm{~cm}$ und $9,25 \mathrm{ccm}$, entsprechend: $0,02924 \mathrm{gr}$ und $0,02913 \mathrm{gr}$ Stickstoff;

Mittel: $0,2919 \mathrm{gr}$ Stickstoff.

Also $5 \mathrm{ccm}$ Harn $=0,02781 \mathrm{gr}$ Stickstoff.

Der Harn enthält im Harnstoff also 0,556\% Stickstoff.

b) Rohr Il. Bestimmung der gebildeten Kohlensäure.

Ablesung am Absorptionsrohr:

$$
\begin{aligned}
& \text { Hgu }=67,0 \quad \text { Kaliber } \begin{cases}36,4=78 \mathrm{~cm} & \mathrm{~T}=8,0^{0} \mathrm{C} . \\
1 \mathrm{~cm}=2,14 \mathrm{~cm} .\end{cases} \\
& \text { Hgo }=36,3 \quad \mathrm{Ba}=762,7 ; \\
& \text { Volum }(\mathrm{V})=78 \mathrm{ccm} ; \text { Druck }(\mathrm{P})=447,06 \mathrm{~mm} ; \\
& \text { Reducirtes Gesammtgas }=44,58 \mathrm{ccm} .
\end{aligned}
$$

Nach Absorption der Kohlensäure durch Kalilauge, deren Wasserspannung $42 \%$ entspricht: 
Ablesung äm Absorptionsrohr:

$$
\begin{aligned}
& \begin{aligned}
\mathrm{Hgu} & =67,15 \\
\mathrm{Hgo} & =24,95 \\
\mathrm{KOH} & =23,95
\end{aligned} \quad \text { Kaliber }\left\{\begin{array}{l}
23,85 \mathrm{~cm}=51,00 \mathrm{ccm} \quad \mathrm{T}=8,2^{\circ} \mathrm{C} . \\
1 \mathrm{~cm}=2,14 \mathrm{~cm} . \mathrm{Ba}=759,5 \mathrm{~mm} .
\end{array}\right. \\
& \mathrm{V}=51,21 ; \quad P=332,63 \mathrm{~mm} \text {. } \\
& \text { Reducirtes Volum 21,76 ccm. }
\end{aligned}
$$

Also: Gefunden $22,82 \mathrm{ccm} \mathrm{CO}_{2}=44,878 \mathrm{mgr} \quad \mathrm{CO}_{2}=61,20 \mathrm{mgr} \stackrel{+}{\mathrm{U}}$ $=0,02855 \mathrm{gr}$ Stickstoff.

5 ccm Harn enthalten also $\mathrm{N}$ in $\stackrel{+}{\mathrm{U}}=0,0272 \mathrm{gr}$ oder der Harn enthält in Harnstoff gebundenen Stickstoff:

$$
0,544 \%
$$

III. Bestimmung des Harnstoffs nach Bunsen in dem Harne, nachdem durch Phosphorwolframsäure, Salzsänre und nachherige Neutralisation die Extractivstoffe ausgefallt sind.

1.

$$
\begin{array}{cl}
200,38 \mathrm{~cm} & \text { Harn } \\
20,00 \# \text { Salzsäure } \\
60,00 " \text { Phosphorwolframsäure } \\
\hline 280,38 \mathrm{~cm} & \text { Mischung. }
\end{array}
$$

Controlversuch ergibt, dass das Volum der Mischung gleich der Summe der Volumina der einzelnen Bestandtheile. Es ist bei der Correctur also nur das Volum des Niederschlags zu berücksichtigen, welcher 0,27 ccm ist. Wo bei der Beschreibung der folgenden Versuche analoge Verhältnisse obwalten, wird einfach das gemessene Volum des Niederschlags angegeben und in Rechnung gestellt. $100 \mathrm{ccm}$ dieser Mischung enthalten also $71,52 \mathrm{ccm}$ Harn. Vom saueren Filtrat werden $200,21 \mathrm{~cm}=143,32 \mathrm{~cm}$ Harn abgemessen und mit Kalkpulver $\left(\mathrm{Ca}(\mathrm{OH})_{2}\right)$ zerrieben, d. h. alkalisch gemacht. Das durch besonderen Versuch festgestellte Volum des Niederschlags $=0,6 \mathrm{ccm}$. Folglich enthalten $5 \mathrm{ccm}$ des Filtrates jetzt 3,589 ccm Harn.

Es soll nun zunächst untersucht werden, wie viel Stickstoff wohl durch Phosphorwolframsäure u. s. w. ausgefällt worden ist.

2. Je $5 \mathrm{ccm}$ des durch $\mathrm{Ca}(\mathrm{OH})_{2}$ alkalischen Filtrates nach $\mathrm{Kjeldah1}$ untersucht. Vorlage $20 \mathrm{ccm} 1 / 10 \mathrm{SO}_{4} \mathrm{H}_{2}$.

Gebraucht 1/10 Hyposulfitlösung 5,55 cem und 5,49 ccm, entsprechend: $0,02029 \mathrm{gr}$ und $0,02036 \mathrm{gr}$ Stickstoff;

Mittel: 0,02032 gr Stickstoff.

$5 \mathrm{ccm}$ Harn enthalten also noch $0,02832 \mathrm{gr}$ Stickstoff; und der ausgefällte Harn enthält noch $0,566 \%$ Stickstoff.

3. Das durch $\mathrm{Ca}(\mathrm{OH})_{2}$ alkalische Filtrat wird mit gleichem Volumen alkalischer $\mathrm{BaCl}_{2}$-Lösung versetzt, je $15 \mathrm{ccm}$ Filtrat eingeschmolzen und 4 Stunden auf $220^{\circ}$ erhitzt. 
a) Rohr I. Bestimmung des gebildeten Ammoniaks.

Vorlage $25 \mathrm{cem} 1 / 10 \mathrm{SO}_{4} \mathrm{H}_{2}$.

1/10 Hyposulfitlösung 4,14 ccm und 4,07 ccm, entsprechend: 0,02929 gr und 0,02939 gr Stickstoff;

Mittel: 0,02934 gr Stickstoff.

$5 \mathrm{ccm}$ Harn also $=0,02721 \mathrm{gr}$ Stickstoff, oder der Harn enthält im Harnstoff 0,544\% Stickstoff.

b) Rohr II. Bestimmung der gebildeten Kohlensäure.

Ablesung am Absorptionsrohr:

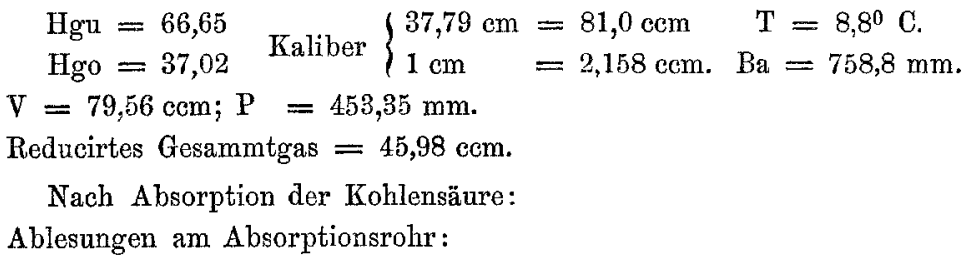

$$
\begin{aligned}
& \mathrm{Hgu}=66,75 \\
& \text { Hgo }=27,35 \\
& \mathrm{KOH}=23,69 \\
& \text { Kaliber }\left\{\begin{array}{l}
23,85 \mathrm{~cm}=51,0 \mathrm{ccm} \quad \mathrm{T}=7,7^{0} \mathrm{C} . \\
1 \mathrm{~cm}=2,14 \mathrm{ccm} . \quad \mathrm{Ba}=758,2 \mathrm{~mm} .
\end{array}\right. \\
& V=50,66 \mathrm{ccm} ; \quad P=356,73 \mathrm{~mm} \text {. } \\
& \text { Reducirtes Gas }=23,12 \mathrm{ccm} \text {. }
\end{aligned}
$$

Folglich 22,86 ccm CO $2=44,96 \mathrm{mgr} \mathrm{CO} 2=61,31 \mathrm{mgr} \stackrel{+}{\mathrm{U}}=0,02861 \mathrm{gr}$ Stickstoff. Demnach $5 \mathrm{ccm}$ Harn $=0,02657 \mathrm{gr}$ Stickstoff oder der Harn enthält in Harnstoff $0,531 \%$ Stickstoff.

IV. Bei der Versetzung der durch Kalk alkalischen Harnmischung mit deralkalischen $\mathrm{BaCl}_{2}-\mathrm{I}_{4} \mathrm{osung}$ war ein allerdings nicht starker Niederschlag entstanden. Es soll gezeigt werden, dass hierdurch kein Stickstoff gefällt worden ist.

Je $5 \mathrm{ccm}$ des Filtrates, welches auch zum Einschmelzen diente, wach Kjeldahl untersucht. Vorlage $10 \mathrm{ccm} 1 / 10 \mathrm{SO}_{4} \mathrm{H}_{2}$.

Gebraucht Hyposulfitlösung 2,58 ccm und 2,59 ccm, entsprechend: $0,01042 \mathrm{gr}$ und $0,01040 \mathrm{gr}$ Stickstoff;

Mittel: 0,01041 gr Stickstoff.

Nun hatte die durch Kalk alkalische Harnmischung vor Versetzung mit dem gleichen Volum $\mathrm{BaCl}_{2}$-Lösung laut den sub III, 1 mitgetheilten Versuchen $0,02032 \mathrm{gr}$ Stickstoff ergeben, so dass $0,01016 \mathrm{gr}$ Stickstoff hätte gefunden werden müssen; es sind aber $0,01041 \mathrm{gr}$ gefunden.

Also ist kein Stickstoff durch die Barytfällung niedergeschlagen worden. 
Tabelle für Versuchserie I.

\begin{tabular}{|c|c|c|c|c|c|c|c|c|}
\hline $\begin{array}{c}\text { Gesammt- } \\
\text { stickstoff } \\
\text { nach } \\
\text { Kjeldahl } \\
\text { in } \%\end{array}$ & $\begin{array}{l}\text { Stickstoff- } \\
\text { gehalt im } \\
\text { ausge- } \\
\text { fällten } \\
\text { Harn } \\
\text { in } \%\end{array}$ & $\begin{array}{c}\text { Stickstoff } \\
\text { Harnst } \\
\text { B unsen } \\
\text { ausgefällt } \\
\text { in } \\
\text { nach der } \\
\mathrm{NH}_{3} \text {-be- } \\
\text { stimmung }\end{array}$ & $\begin{array}{l}\text { gehalt in } \\
\text { off nach } \\
\text { im nicht } \\
\text { ten Harn } \\
\% \\
\text { nach der } \\
\mathrm{CO}_{2} \text {-be- } \\
\text { stimmung }\end{array}$ & \begin{tabular}{|} 
Stickstoff \\
Harnsto \\
Bunsen \\
gefälite \\
in \\
nach NH \\
bestim- \\
mung
\end{tabular} & $\begin{array}{l}\text { gehalt in } \\
\text { off nach } \\
\text { im aus- } \\
\text { on Harn } \\
\% \\
\text { nach } \mathrm{CO}_{2} \text { - } \\
\text { bestim- } \\
\text { mung }\end{array}$ & $\begin{array}{c}\% \text { des } \\
\text { Stickstoff } \\
\text { nicht im } \\
\text { Harnstoff. } \\
\text { Ge- } \\
\text { sammt- } \\
\text { sticks toff } \\
=100\end{array}$ & $\begin{array}{c}\begin{array}{c}\text { Fehler } \\
\text { der }\end{array} \\
\text { Methode } \\
\text { in } \% \text { des } \\
\text { Stickstoff }\end{array}$ & $\begin{array}{c}\text { Durch } \\
\text { Säuren } \\
\text { ausge- } \\
\text { fällter } \\
\text { Stickstoff } \\
\text { in } \%\end{array}$ \\
\hline 0,588 & 0,566 & 0,556 & 0,544 & 0,544 & 0,531 & 9,7 & $+2,4$ & 3,8 \\
\hline
\end{tabular}

Dieser Versuch ergibt also ein Resultat, welches ganz übereinstimmt mit demjenigen, das Bunsen erhielt, als er die ,Extractivstoffe" mit Bleiessig ausfällte. - Auffallend ist aber hier die grosse Menge stickstoff haltiger Körper, die neben dem Harnstoff im Harne enthalten ist, sowie, dass also von diesen stickstoffhaltigen Extractivstoffen noch nicht einmal die Hälfte durch Phosphorwolframsäure a. s. w. ausgefällt worden ist. Diese müssen dafür verantwortlich gemacht werden, dass die Menge des Ammoniaks, welche im zugeschmolzenen Rohr auftritt, ein wenig grösser ist, als es der Theorie entspricht und als dies bei reinen Harnstofflösungen gefunden wird.

\section{Versuchsserie II.}

\section{Harn IV.}

I. Bestimmung des Gesammtstickstoffs.

Je $5 \mathrm{ccm}$ Harn mit $40 \mathrm{ccm}$ rauchender Schwefelsäure 10 Stunden gekocht. Vorlage $47 \mathrm{ccm} 1 / 10 \quad \mathrm{SO}_{4} \mathrm{H}_{2}$.

Gebraucht $1 / 10$ Hyposulfitlösung 4,68 ccm und 4,62 ccm, entsprechend: 0,05942 and $0,05950 \mathrm{gr}$ Stickstoff;

Mittel: $0,05946 \mathrm{gr}$ Stickstoff.

Harn enthält also 1,189\% Stickstoff. 
II. Bestimmung des Harnstoffs im ausgefällten Harne nach Bunsen.

1.

$$
\begin{aligned}
200,1 \mathrm{ccm} & \text { Harn } \\
20,0 & \# \text { Salzsäure } \\
100,0 \% & \text { Phosphorwolframsäure }
\end{aligned}
$$

$320,1 \mathrm{ccm}$ Mischung.

Volumen des entstandenen Niederschlags $=0,71 \mathrm{ccm}$.

Von dieser filtrirten Mischung wurden $200,26 \mathrm{ccm}=125,46 \mathrm{ccm}$ Harn mit Kalkpulver alkalisch gemacht, vom Filtrat $50 \mathrm{ccm}$ mit $50 \mathrm{ccm}$ alkalischer $\mathrm{BaCl}_{2}$-Lösung versetzt und vom Filtrat je $15 \mathrm{ccm}=4,66 \mathrm{ccm}$ Harn eingeschmolzen. Bei der Neutralisation mit $\mathrm{Ca}(\mathrm{OH})_{2}$ fand eine Expansion von $2,6 \mathrm{ccm}$ statt; Volum des Niederschlags war $0,93 \mathrm{ccm}$; folglich bleibt eine Volumzunahme von 1,67 ccm. Demgemäss enthalten $100 \mathrm{ccm}$ der alkalischen einzuschmelzenden Flüssigkeit $31,07 \mathrm{ccm}$ Harn.

2. a) Rohr I. Inhalt wird zur Bestimmung des Ammoniaks abdestillirt mit $30 \mathrm{ccm}$ Natronlauge $(1,25 \mathrm{sp}$. Gew.), der noch circa $500 \mathrm{ccm}$ Wasser zugesetzt wurden. Vorlage $40 \mathrm{~cm} 1 / 10 \mathrm{SO}_{4} \mathrm{H}_{2}$.

Gebrancht $1 / 10$ Hyposulfitlösung 4,39 ccm, entsprechend: 0,04998 gr Stickstoff; also $5 \mathrm{ccm}$ Harn $=0,05363 \mathrm{gr}$ Stickstoff.

b) Rohr II. Ammoniak nach Zusatz von Magnesia destillirt. Vorlage $40 \mathrm{ccm} 1 / 10 \mathrm{SO}_{4} \mathrm{H}_{2}$.

Gebraucht 1/10 Hyposulfitlösung 5,35 ccm, entsprechend: 0,04865 gr Stickstoff;

$$
\begin{aligned}
\text { also } 5 \mathrm{ccm} \text { Harn } & =0,05220 \mathrm{gx} \text { Stickstoff } \\
\text { Mittel } & =0,05291, ",
\end{aligned}
$$

Harn enthält Stickstoff in Harnstoff $1,085 \%$.

c) Rohr III. Bestimmung der Kohlensäure.

$$
\begin{aligned}
& \begin{array}{l}
\text { Hgu }=66,50 \\
\text { Hgo }=42,72
\end{array} \quad \text { Kaliber }\left\{\begin{array}{l}
43,25 \mathrm{~cm}=93 \mathrm{~cm} \quad \mathrm{~T}=7,7^{0} \mathrm{C} . \\
1 \mathrm{~cm}=2,206 \quad \mathrm{Ba}=755,8 \mathrm{~mm}
\end{array}\right. \\
& \mathrm{V}=92,05 \mathrm{ccm} ; \quad \mathrm{P}=509,45 \mathrm{~mm} \text {. } \\
& \text { Reducirtes Gesammtgas }=60,011 \mathrm{ccm} \text {. }
\end{aligned}
$$

Nach Absorption der Kohlensäure:

$$
\begin{aligned}
& \mathrm{Hgu}=66,65 \\
& \mathrm{Hgo}=27,30 \\
& \mathrm{KOH}=23,53
\end{aligned} \quad \text { Kaliber }\left\{\begin{array}{l}
23,85 \mathrm{~cm}=51 \mathrm{ccm} \quad \mathrm{T}=6,6^{0} \mathrm{C} . \\
1 \mathrm{~cm}=2,14 \mathrm{~cm} \quad \mathrm{Ba}=744,5 \mathrm{~mm} ; \\
\mathrm{V}=50,315 \mathrm{ccm} ; \mathrm{P}=343,78 \mathrm{~mm} . \\
\text { Reducirtes restirendes Gas }=22,22 \mathrm{~cm} .
\end{array}\right.
$$


Nochmalige Ablesung am nächsten Tage:

$$
\begin{gathered}
\mathrm{Hgu}=66,65 \\
\mathrm{Hgo}=27,64 \quad \text { Kaliber }\left\{\begin{array}{l}
23,85=51 \mathrm{~cm} \quad \mathrm{~T}=6,6^{\circ} \mathrm{C} . \\
1 \mathrm{~cm}=2,14 \quad \mathrm{Ba}=735, \mathrm{G}
\end{array}\right. \\
\mathrm{KOH}=23,85 \\
\quad \text { Reducirtes restirendes Gas }=22,24 .
\end{gathered}
$$

Also: $37,79 \mathrm{ccm} \mathrm{CO}_{2}=74,318 \mathrm{mgr} \mathrm{CO}_{2}=101,34 \mathrm{mgr}$ Harnstoff

$$
=0,04729 \mathrm{gr} \text { Stickstoff. }
$$

d) Rohr IV. Kohlensäurebestimmung.

$$
\begin{gathered}
\text { Hgu }=66,76 \quad \text { Kaliber }\left\{\begin{array}{l}
41,89 \mathrm{~cm}=90 \mathrm{~cm} \quad \mathrm{~T}=6,50 \mathrm{C} . \\
1 \mathrm{~cm}=2,16 \mathrm{~cm} \quad \mathrm{Ba}=765,9 \mathrm{~mm} ;
\end{array}\right. \\
\text { Hgo }=41,36=89,08 ; \mathrm{P}=504,09 . \\
\text { Reducirtes Gesammtgas }=57,71 \mathrm{ccm} .
\end{gathered}
$$

Nach Absorption der Kohlensäure:

$$
\begin{gathered}
\mathrm{Hgu}=66,86 \\
\mathrm{Hgo}=23,70 \\
\mathrm{KOH}=22,10
\end{gathered} \quad \text { Kaliber }\left\{\begin{array}{l}
22,45 \mathrm{~cm}=48 \mathrm{~cm} \quad \mathrm{~T}=8,0^{\circ} \mathrm{C} . \\
1 \mathrm{~cm}=2,14 \mathrm{~cm} \quad \mathrm{Ba}=764,5 \mathrm{~mm} ; \\
\mathrm{V}=47,25 \mathrm{ccm} ; \mathrm{P}=327,47 \mathrm{~mm} .
\end{array}\right.
$$

Folglich $37,93 \mathrm{ccm} \mathrm{CO}_{2}=74,593 \mathrm{mgr} \mathrm{CO} \mathrm{CO}_{2}=101,72 \mathrm{mgr}$ Harnstoff

$$
=0,04747 \mathrm{gr} \text { Stickstoff. }
$$

Mittel aus beiden $\mathrm{CO}_{2}$-Analysen: $0,04738 \mathrm{gr}$ Stickstoff.

$5 \mathrm{ccm}$ Harn also $=0,05084 \mathrm{gr}$ Stickstoff.

Der Harn enthält im Harnstoff 1,017\% Stickstoff.

3. Beweis, dass der Barytniederschlag keinen Stickstoff gefällt hat.

a) Je $5 \mathrm{ccm}$ der mit Kalk alkalisirten Harnmischung mit $40 \mathrm{ccm}$ rauchender Schwefelsäure 10 Stunden gekocht. Vorlage $30 \mathrm{ccm} 1 / 10 \mathrm{SO}_{4} \mathrm{H}_{2}$.

Gebraucht $1 / 10$ Hyposulfitlösung $5,45 \mathrm{ccm}$ und $5,48 \mathrm{ccm}$, entsprechend im Mittel: 0,03445 gr Stickstoff; also $5 \mathrm{ccm}$ Harn $=0,05544 \mathrm{gr}$ Stickstoff

oder der Harn enthielt nach Ausfällung mit den Säuren und Neutralisation: $1,110 \%$ Stickstoff.

b) Je $5 \mathrm{ccm}$ der nach Zusatz der alkalischen $\mathrm{BaCl}_{2}$-Lösung entstandenen Mischung ergeben:

Vorlage $15 \mathrm{ccm} 1 / 10 \quad \mathrm{SO}_{4} \mathrm{H}_{2}$.

Gebraucht $1 / 10$ Hyposulfitlösung 2,78 com und 2,68 ccm, entsprechend im Mittel: 0,01726 gr Stickstoff. Nach II, 3 a müsste es sein: $0,01722 \mathrm{gr}$ Stickstoff. 
Tabelle za Versuchserie II.

\begin{tabular}{|c|c|c|c|c|c|}
\hline $\begin{array}{l}\text { Gesammt- } \\
\text { stickstoff } \\
\text { nach } \\
\text { Kjeldahl } \\
\text { in } \%\end{array}$ & $\begin{array}{c}\text { Stickstoff } \\
\text { gehalt im } \\
\text { ausgefällten } \\
\text { Harn in } \%\end{array}$ & \begin{tabular}{|} 
Stickstoffgeh \\
stoff nach \\
$\%$ berechn \\
gefällte \\
aus der \\
$\mathrm{NH}_{\mathrm{3}}$-bestim- \\
mung
\end{tabular} & $\begin{array}{l}\text { aalt in Harn- } \\
\text { Bunsen in } \\
\text { aet im aus- } \\
\text { en Harn } \\
\text { aus der } \\
\mathrm{CO}_{2} \text {-bestim- } \\
\text { mung }\end{array}$ & $\begin{array}{c}\% / 0 \text {-Gehalt } \\
\text { des nicht in } \\
\text { Harnstoff } \\
\text { enthaltenen } \\
\text { Stickstoffs. } \\
\text { Gesammt- } \\
\text { stickstoffs } \\
=100\end{array}$ & $\begin{array}{c}\text { Durch } \\
\text { Säuren aus- } \\
\text { gefällter } \\
\text { Stickstoff } \\
\text { in } \%\end{array}$ \\
\hline 1,189 & 1,110 & 1,058 & 1,017 & 15,9 & 6,6 \\
\hline
\end{tabular}

\section{Versuchsserie III.}

\section{Harn IV.}

\section{Gesammtstickstoff.}

Je $5 \mathrm{ccm}$ Harn mit $40 \mathrm{ccm}$ rauchender Schwefelsäure 10 Stunden gekocht. Vorlage am Destillirapparat: $47 \mathrm{~cm} 1 / 10 \quad \mathrm{SO}_{4} \mathrm{H}_{2}$.

$1 / 10$ Hyposulfit-lösung $6,17 \mathrm{ccm} ; 6,04 \mathrm{ccm} ; 6,13 \mathrm{ccm}$;

entsprechend Stickstoff $0,05733 \mathrm{gr} ; 0,05751 \mathrm{gr} ; 0,05739 \mathrm{gr}$.

Mittel: $0,5741 \mathrm{gr}$ Stickstoff.

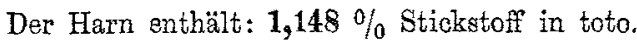

II. Harnstoffbestimmung nach Bunsen in dem Harne ohne

Ausfällung mit Phosphorwolframsäure.

1. $40 \mathrm{ccm}$ Harn mit Wasser auf $100 \mathrm{ccm}$ verdünnt; $50 \mathrm{ccm}$ dieser Mischung mit $50 \mathrm{ccm}$ alkalischer $\mathrm{BaCl}_{2}$-Lösung versetzt, filtrirt und rom Filtrat je $15 \mathrm{ccm}=3 \mathrm{ccm}$ Harn eingeschmolzen. Die Alkalescenz dieser $15 \mathrm{ccm}$ betrug $=14,0 \mathrm{~cm} 1 / 10$ Alkali.

2. a) Ammoniakbestimmung.

Vorlage $30 \mathrm{ccm} 1 / 10 \mathrm{SO}_{4} \mathrm{H}_{2}$.

Rohr I. Destillirt mit $30 \mathrm{ccm}$ Natronlauge $(1,25$ sp. G.) und Wasser: Hyposulfitlösung: $7,29 \mathrm{ccm}$ entsprechend $0,03189 \mathrm{gr}$ Stickstoff.

Rohr II. Destillirt mit $\mathrm{MgO}$ :

Hyposulfitlösung: 7,8 ccm entsprechend $0,03187 \mathrm{gr}$ Stickstoff.

Mittel: $0,03188 \mathrm{gr}$ Stickstofi.

Für $5 \mathrm{ccm}=0,05313 \mathrm{gr}$ Stickstoff.

Der Harn enthält also $1,063 \%$ Stickstoff in Harnstoff. 
b) Kohlensäurebestimmung.

Rohr III.

$$
\begin{aligned}
& \text { Hgu }=65,60 \\
& \text { Hgo }=38,00
\end{aligned} \text { Kaliber } \begin{cases}38,15 \mathrm{~cm}=81 \mathrm{~cm} & \mathrm{~T}=7,0^{\circ} \mathrm{C} . \\
1 \mathrm{~cm}=2,143 \mathrm{ccm} & \text { Ba }=753,0 \mathrm{~mm} .\end{cases}
$$

$\mathrm{V}=80,89 \mathrm{ccm} ; \mathrm{P}=468,94 \mathrm{~mm}$.

Reducirtes Gesammtgas $=48,664 \mathrm{ccm}$.

Nach Absorption der Kohlensäure:

$$
\begin{aligned}
& \begin{array}{l}
\text { Hgu }=65,72 \\
\text { Hgo }=25,27 \\
\text { KOH }=24,00
\end{array} \quad \text { Kaliber } \begin{cases}24,11 \mathrm{~cm}=51 \mathrm{~cm} & \mathrm{~T}=6,40 \mathrm{C} . \\
1 \mathrm{~cm}=2,128 \mathrm{ccm} & \mathrm{Ba}=755,6 \mathrm{~mm} .\end{cases} \\
& \mathrm{V}=50,77: \mathrm{P}=347,43 \mathrm{~mm} \text {. } \\
& \text { Reducirtes restirendes Gas }=22,678 \mathrm{~cm} \text {. }
\end{aligned}
$$
Stickstoff.

Folglich : $25,986 \mathrm{ccm} \mathrm{CO} C_{2}=51,104 \mathrm{mgr} \mathrm{CO}_{2}=69,687 \mathrm{mgr} \stackrel{+}{\mathrm{U}}=0,03252 \mathrm{gr}$

$5 \mathrm{ccm}$ Harn also $=0,05420 \mathrm{gr}$ Stickstoff in Harnstoff.

Rohr IV,

$$
\begin{gathered}
\text { Hga }=65,00 \quad \text { Kaliber } \begin{cases}35,35 \mathrm{~cm}=75 \mathrm{~cm} & \mathrm{~T}=9,0 . \\
1 \mathrm{~cm}=2,19 \mathrm{~cm} & \mathrm{Ba}=749,42 \mathrm{~mm} . \\
\text { Hgo }=34,70 \quad \mathrm{~V}=73,795 \mathrm{~cm} ; \mathrm{P}=447,15 \mathrm{~mm} .\end{cases} \\
\text { Reducirtes Gas }=42,033 \mathrm{ccm} .
\end{gathered}
$$

Nach Absorption der Kohlensäure:

$$
\begin{aligned}
\mathrm{Hgu} & =65,20 \\
\mathrm{Hgo} & =20,70 \\
\mathrm{KOH} & =18,85
\end{aligned} \quad \text { Kaliber } \begin{cases}19,85 \mathrm{~cm}=42 \mathrm{~cm} & \mathrm{~T}=8,3^{0} \mathrm{C} . \\
1 \mathrm{~cm}=2,08 \mathrm{~cm} & \mathrm{Ba}=760,05 \mathrm{~mm} .\end{cases}
$$

Reducirtes restirendes Gas $=\mathbf{1 5 , 7 7} \mathrm{ccm}$.

Folglich : $26,263 \mathrm{ccm} \mathrm{CO} \mathrm{CO}_{2}=51,649 \mathrm{mgr} \mathrm{CO}_{2}=70,42 \mathrm{mgr} \stackrel{+}{\mathrm{U}}=0,03287 \mathrm{gr}$ Stickstoff.

$5 \mathrm{ccm}$ Harn also $=0,05478 \mathrm{gr}$ Stickstoff in Harnstoff.

Mittel: $0,05449 \mathrm{gr}$ Stickstoff im Harnstoff.

Der Harn enthält also: 1,090\% Stickstoff in Harnstoff.

III. Harnstoffbestimmung nach Bunsen nach Entfernung der durch Phosphorwolframsäure fällbaren Extractivstoffe.

1.

$$
\begin{aligned}
& 200,26 \mathrm{ccm} \text { Harn } \\
& 20,00 \# \text { Salzsäure } \\
& 100,00 " \text { Phosphorsäure } \\
& \hline 320,26 \mathrm{~cm} \\
& \text { Mischung. }
\end{aligned}
$$

Das Volum des entstandenen Niederschlags betrug $0,76 \mathrm{ccm}$.

$200,26 \mathrm{~cm}$ des Filtrates $=125,5 \mathrm{ccm}$ Harn wurden mit Kalkpulver $\left(\mathrm{Ca}(\mathrm{OH})_{2}\right)$ zerrieben und alkalisch gemacht. Bei der Ausfälìng mit $\mathrm{Ca}(\mathrm{OH})_{2}$ fand eine Expansion von 4,2 ccm statt, das Volum des Niederschlags betrug 1,5 ccm, sodass ein Plus von 2,7 ccm Expansion bleibt. Das Filtrat wurde mit 
gleichem Volum alkalischer $\mathrm{BaCl}_{2}$-Lösung versetzt und jo $15 \mathrm{ccm}$ eingeschmolzen. $100 \mathrm{ccm}$ dieser Mischung $=30,915 \mathrm{ccm}$ Harn. $15 \mathrm{ccm}=4,64 \mathrm{ccm}$. (Uncorrigirt: $4,69 \mathrm{ccm}$.)

2. a) Ammoniakbestimmung.

Rohr I. Vorlage $44 \mathrm{ccm} 1 / 10 \mathrm{SO}_{4} \mathrm{H}_{2}$.

Destillation mit $30 \mathrm{ccm}$ Natronlauge $(1,24 \mathrm{sp}$. G.) und Wasser:

$1 / 10$ Hyposulfitlösung $=10,48 \mathrm{ccm}: 0,04706 \mathrm{gr}$ Stickstoff.

Rohr II.

Destillation mit $\mathrm{MgO}$ :

1/10 Hyposulfitlösung $=10,30 \mathrm{ccm}: 0,04731 \mathrm{gr}$ Stíckstoff.

Nittel $=0,04719 \mathrm{gr}$ Stickstoff;

$5 \mathrm{ccm}$ Harn also: $0,05085 \mathrm{gr}$ Stickstoff in Harnstoff;

Harn enthält also: $1,0170 \% \quad " \quad "$

b) Kohlensäurebestimmung.

Rohr III.

Hgu $=66,36$
Hgo $=40,35$$\quad$ Kaliber $\begin{cases}40,50 \mathrm{~cm}=87 \mathrm{~cm} & \mathrm{~T}=7,0^{\circ} \mathrm{C} . \\ 1 \mathrm{~cm}=2,22 \mathrm{~cm} & \mathrm{Ba}=759,8 \mathrm{~mm} .\end{cases}$

$\mathrm{V}=86,90 ; \mathrm{P}=491,61 \mathrm{~mm}$.

Reducirtes Gesammtgas $=54,807 \mathrm{ccm}$.

Nach Absorption der Kohlensäure:

$$
\begin{aligned}
\text { Hgu } & =66,62 \\
\mathrm{Hgo} & =22,65 \\
\mathrm{KOH} & =21,05
\end{aligned} \quad \text { Kaliber } \begin{cases}21,05 \mathrm{~cm}=45 \mathrm{ccm} & \mathrm{T}=7,5^{\circ} \mathrm{C} . \\
\mathrm{V}=45,0 \mathrm{~cm} ; \quad \mathrm{P}=315,10 \mathrm{~mm} . & \mathrm{Ba}=760,05 \mathrm{~mm} .\end{cases}
$$

Reducirtes restirendes Gas $=18,158 \mathrm{ccm}$.

Folglich : $36,649 \mathrm{ccm} \quad \mathrm{CO}_{2}=72,074 \mathrm{mgr}=98,28 \mathrm{mgr} \stackrel{\stackrel{+}{\mathrm{U}}}{\mathrm{H}}=0,04587 \mathrm{gr}$ Stickstoff.

Also $5 \mathrm{ccm}$ Harn $=0,04943 \mathrm{gr}$ Stickstoff in Harnstoff.

Rohr IV.

$$
\begin{gathered}
\text { Hgu }=66,11 \quad \text { Kaliber } \begin{cases}40,50=87 \mathrm{~cm} & \mathrm{~T}=9,40 \mathrm{C} . \\
1 \mathrm{~cm}=2,22 \mathrm{~cm} & \mathrm{Ba}=759,31 \mathrm{~mm} . \\
\text { Hgo }=40,45 \quad \mathrm{C}=493,09 \mathrm{~mm} .\end{cases} \\
\mathrm{V}=87,11 \mathrm{ccm} ; \quad \mathrm{P}=2,638 \mathrm{~cm} .
\end{gathered}
$$

Nach Absorption der Kohlensäure:

$$
\begin{aligned}
& \begin{array}{l}
\mathrm{Hgu}=66,37 \\
\mathrm{Hgo}=23,31 \\
\mathrm{KOH}=20,60
\end{array} \quad \text { Kaliber } \begin{cases}21,05 \mathrm{~cm}=45 \mathrm{~cm} & \mathrm{~K}=9,3^{\circ} \mathrm{C} . \\
1 \mathrm{~cm}=2,13 \mathrm{ccm} & \mathrm{Ba}=758,9 \mathrm{~mm} .\end{cases} \\
& \mathrm{V}=44,04 \mathrm{ccm} ; \quad \mathrm{P}=321,41 \mathrm{~mm} \text {. } \\
& \text { Reducirtes restirendes Gas }=18,012 \text {. }
\end{aligned}
$$

Folglich: $36,626 \mathrm{ccm} \mathrm{CO}$ CO$_{2}=72,03 \mathrm{mgr} \mathrm{CO}_{2}=98,223 \mathrm{mgr} \stackrel{+}{\mathrm{U}}=0,04589 \mathrm{gr}$ Stickstoff.

5 cem Harn also $=0,04940 \mathrm{gr}$ Stickstoff. 
Verbesserung der Harnstoff-Analyse nach Bunsen etc.

5 ccm Harn im Mittel also $=0,04942 \mathrm{gr}$ Stickstoff in Harnstoff.

Der Harn enthält also $0,988 \%$ " " "

Tabelle von Versuchserie III.

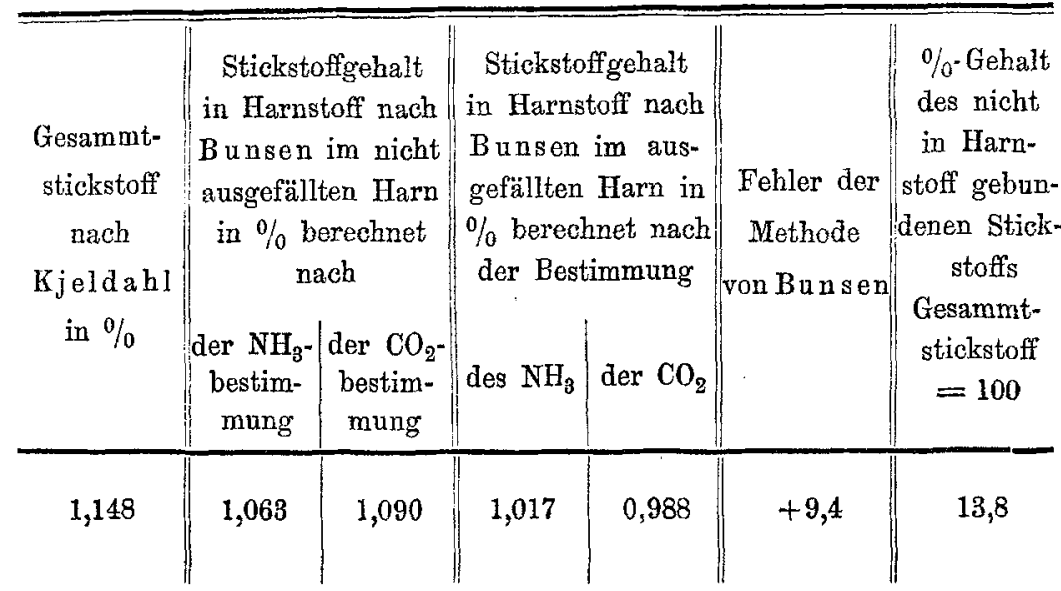

Versuchsserie IV.

Harn III.

I. Gesammtstickstoff.

Je $5 \mathrm{ccm}$ Harn mit $40 \mathrm{ccm}$ rauchender Schwefelsäure 10 Stunden gekocht. Vorlage $47 \mathrm{~cm} 1 / 10 \mathrm{SO}_{4} \mathrm{H}_{2}$.

1/10 Hyposulfitlösung: $5,09 \mathrm{ccm}$ und $5,03 \mathrm{ccm}$;

entsprechend: $0,05884 \mathrm{gr}$ und $0,05893 \mathrm{gr}$ Stickstoff;

Mittel $=0,5888 \mathrm{gr}$ Stickstoff;

Harn enthält: $1,1777 \%$ Stickstoff in toto.

II. Harnstoffbestimmung nach Bunsen ohne Ausfällang der "Extractivstoffe".

1. $40 \mathrm{ccm}$ Harn auf $100 \mathrm{~cm}$ verdünnt; $50 \mathrm{~cm}$ dieser Mischung mit $50 \mathrm{ccm}$ alkalischer $\mathrm{Ba}_{2} \mathrm{Cl}$-Lösung versetzt und vom Filtrat je $15 \mathrm{ccm}=3 \mathrm{ccm}$ Harn eingeschmolzen. Die Alkalescenz der $15 \mathrm{ccm}$ entspricht $14,4 \mathrm{~cm} 1 / 10$ Alkali.

2. a) Ammoniakbestimmung. Vorlage $30 \mathrm{~cm} 1 / 10 \mathrm{SO}_{4} \mathrm{H}_{2}$.

Rohr I. Mit $37 \mathrm{ccm}$ Natronlauge $(1,24 \mathrm{sp}$. G.) und Wasser destillirt: $1 / 10$ Hyposulfit]ösung $=6,12 \mathrm{ccm}: 0,03353 \mathrm{gr}$ Stickstoff. 
Rohr II. Mit MgO destillirt:

$1 / 10$ Hyposulfitlösung $=6,00 \mathrm{ccm}: 0,3370 \mathrm{gr}$ Stickstoff;

Mittel $=0,03361$ gr Stickstoff;

$5 \mathrm{ccm}$ Harn also $=0,05602 \mathrm{gr}$ Stickstoff.

Also Harn enthält 1,120\% Stickstoff in Harnstoff.

b) Kohlensäurebestimmung.

Rohr III.

$$
\begin{aligned}
& \text { Hgu }=66,61 \\
& \text { Hgo }=33,70
\end{aligned} \quad \text { Kaliber } \begin{cases}33,60 \mathrm{~cm}=72 \mathrm{~cm} & \mathrm{~T}=6,4^{0} \mathrm{C} . \\
1 \mathrm{~cm}=2,14 \mathrm{ccm} & \mathrm{Ba}=755,6 \mathrm{~mm} .\end{cases}
$$

$\mathrm{V}=72,42 ; \mathrm{P}=418,84 \mathrm{~mm}$.

Redueirtes Gesammtgas $=39,00 \mathrm{ccm}$.

Nach Absorption der Kohlensäure:

$$
\begin{aligned}
& \text { Hgu }=66,75 \\
& \text { Hgo }=18,19 \text { Kaliber } \begin{cases}16,83 \mathrm{~cm}=36 \mathrm{~cm} & \mathrm{~T}=7,1^{\circ} \mathrm{C} . \\
1 \mathrm{~cm}=2,113 \mathrm{ccm} & \mathrm{Ba}=755,6 \mathrm{~mm} .\end{cases} \\
& \mathrm{KOH}=16,25 \\
& \mathrm{~V}=34,78 ; \quad \mathrm{P}=264,57 . \\
& \text { Reducirtes restirendes Gas }=11,797 \mathrm{~cm} .
\end{aligned}
$$

Folglich: $27,2 \mathrm{ccm} \mathrm{CO}_{2}=53,492 \mathrm{mgr} \quad \mathrm{CO}_{2}=72,96 \mathrm{mgr} \quad \stackrel{+}{\mathrm{U}}=0,03404 \mathrm{gr}$ Stickstoff.

$5 \mathrm{ccm}$ Harn also $=0,05673 \mathrm{gr}$ Stickstoff.

Rohr IV.

Hgu $=65,96$
Hgo $=38,35$$\quad$ Kaliber $\begin{cases}39,15 \mathrm{~cm}=84 \mathrm{~cm} & \mathrm{~T}=9,0^{\circ} \mathrm{C} . \\ 1 \mathrm{~cm}=2,21 \mathrm{ccm} & \mathrm{Ba}=759,62 .\end{cases}$

$\mathrm{V}=82,46 \mathrm{~cm} ; \quad \mathrm{P}=474,01 \mathrm{~mm}$.

Reducirtes Gesammtgas $=49,791 \mathrm{ccm}$.

Nach Absorption der Kohlensäure;

$$
\begin{aligned}
& \text { Hgu }=66,16 \\
& \text { Hgo }=25,80 \\
& \mathrm{KOH}=23,80
\end{aligned} \quad \text { Kaliber } \begin{cases}23,85 \mathrm{~cm}=51 \mathrm{~cm} & \mathrm{~T}=8,3^{\circ} \mathrm{C} . \\
1 \mathrm{~cm}=2,14 \mathrm{~cm} & \mathrm{Ba}=760,05 \mathrm{~mm} .\end{cases}
$$

$\mathrm{V}=50,9 \mathrm{ccm} ; \quad \mathrm{P}=350,55 \mathrm{~mm}$

Reducirtes restirendes Gas $=22,78 \mathrm{ccm}$.

Folglich : $27,01 \mathrm{ccm} \quad \mathrm{CO}_{2}=53,12 \mathrm{mgr} \quad \mathrm{CO}_{2}=72,44 \mathrm{mgr} \stackrel{+}{\mathrm{U}}=0,03380 \mathrm{gr}$ Stickstoff.

Also $5 \mathrm{ccm}$ Harn $=0,05635 \mathrm{gr}$ Stickstoff;

$$
\text { Mittel }=0,05654, \quad,
$$

Harn enthält also: 1,131\% Stickstoff in Harnstoff.

III. Harnstoffbestimmung nach Bunsen mit Elimination der durch Phosphorwolframsäure fällbaren "Extractivstoffe“.

1.

$$
\begin{aligned}
200,38 \mathrm{~cm} & \text { Harn } \\
20,00 & \Rightarrow \text { Salzsäure } \\
120,00 & \text { Phosphorwolframsäure }
\end{aligned}
$$

$340,38 \mathrm{ccm}$ Mischung. 
Volum des entstandenen Niederschlages $=0,82 \mathrm{~cm} . \quad 200,38 \mathrm{ccm}$ des Filtrates $=118,244 \mathrm{ccm}$ Harn und Kalkpulver alkalisch gemacht, das Filtrat mit gleichem Volum alkalischer Chlorbariumlösung verzetzt und von dem Filtrat hiervon je $15 \mathrm{ccm}$ eingeschmolzen. Bei der Ausfällung mit $\left(\mathrm{Ca}(\mathrm{OH})_{2}\right.$ betrug die Expansion 5,7 ccm; das Volum des Niederschlags 2,0 ccm, folglich Plus an Expansion $=3,7 \mathrm{ccm}$, $15 \mathrm{ccm}$ der alkalischen $\mathrm{BaCl}_{2}$-Harmmischung also $=4,3455 \mathrm{ccm}$ Harn.

2. a) Ammoniakbestimmung. Vorlage $40 \mathrm{ccm} 1 / 10 \mathrm{SO}_{4} \mathrm{H}_{2}$.

Rohr I. Mit Natronlauge destillirt;

1/10 Hyposulfitlösung $=7,3 \mathrm{ccm}: 0,04591 \mathrm{gr}$ Stickstoff.

Roh r II. Mis MgO destillirt:

1/10 Hyposulfitlosung $=7,1 \mathrm{ccm}: 0,04619 \mathrm{gr}$ Stickstoff:

Mittel : 0,04605 .

$5 \mathrm{ccm}$ Harn also $=0,05299 \mathrm{gr}$ Stickstoff.

Harn enthält 1,0598 $=1,060 \%$ Stickstoff an Harnstoff gebunden.

b) Kohlensäurebestimmung.

Rohr III.

$$
\begin{aligned}
& \begin{array}{l}
\text { Hgu }=64,97 \\
\text { Hgo }=40,00
\end{array} \text { Kaliber } \begin{cases}40,95 \mathrm{~cm}=87 \mathrm{ccm} & \mathrm{T}=7,00 \mathrm{C} . \\
1 \mathrm{~cm}=2,143 \mathrm{ccm} & \mathrm{Ba}=759,8 \mathrm{~mm} .\end{cases} \\
& \mathrm{V}=85,18 \mathrm{ccm} ; \quad \mathrm{P}=502,00 \mathrm{~mm} \text {. } \\
& \text { Reducirtes Gesammtgas }=54,858 \mathrm{ccm} \text {. }
\end{aligned}
$$

Nach Absorption der Kohlensäure:

$$
\begin{aligned}
& \text { Hgu }=65,25 \\
& \mathrm{HOH}=22,85
\end{aligned} \quad \text { Kaliber } \begin{cases}21,27 \mathrm{~cm}=45 \mathrm{~cm} & \mathrm{~T}=7,5^{0} \mathrm{C} . \\
1 \mathrm{~cm}=2,11 \mathrm{ccm} & \mathrm{Ba}=760,5 \mathrm{~mm} .\end{cases}
$$

Reducirtes restirendes Gas $=18,855 \mathrm{ccm}$.

Stickstoff.

Folglich : $36,003 \mathrm{ccm} \mathrm{CO}_{2}=70,804 \mathrm{mgr} \mathrm{CO}_{2}=96,55 \mathrm{mgr} \stackrel{+}{\mathrm{U}}=0,04506 \mathrm{gr}$

$5 \mathrm{ccm}$ Harn also $=0,05185 \mathrm{gr}$ Stickstoff.

Rohr IV.

$$
\begin{aligned}
& \text { Hgu }=65,96 \quad \text { Kaliber } \begin{cases}51,45 \mathrm{~cm}=111 \mathrm{~cm} \\
1 \mathrm{~cm}=2,22 \mathrm{~cm}\end{cases} \\
& \text { Hgo }=51,56 \quad \mathrm{~T}=11,5^{0} \mathrm{C} . \\
& \mathrm{V}=111,46 \mathrm{ccm} ; \mathrm{P}=607,8 \mathrm{~mm} . \\
& \text { Reducirtes Gesammtgas }=85,54 \mathrm{ccm} .
\end{aligned}
$$

Folglich: $36,08 \mathrm{ccm} \mathrm{CO}_{2}=79,955 \mathrm{mgr} \mathrm{CO}_{2}=96,76 \mathrm{mgr} \stackrel{+}{\mathrm{U}}=0,04515 \mathrm{gr}$ Stickstoff. 


$$
\begin{aligned}
5 \mathrm{ccm} \text { also } & =0,05192 \mathrm{gr} \text { Stickstoff. } \\
\text { Mittel } & =0,05188 \mathrm{gr} \text { Stickstoff. }
\end{aligned}
$$

Der Harn enthält also 1,038\% Stickstoff an Harnstoff gebunden.

\begin{tabular}{|c|c|c|c|c|c|c|}
\hline \multirow{2}{*}{$\begin{array}{l}\text { Gesammt- } \\
\text { stickstoff } \\
\text { nach } \\
\text { Kjel dahI } \\
\text { in } \%\end{array}$} & \multicolumn{2}{|c|}{$\begin{array}{c}\text { Stickstoff in Harn- } \\
\text { stoff nach Bunsen } \\
\text { im nicht ausge- } \\
\text { fällten Harn in } \% \\
\text { berechnet nach } \\
\text { der Bestimmung } \\
\text { von }\end{array}$} & \multicolumn{2}{|c|}{$\begin{array}{l}\text { Stickstoff in Harm- } \\
\text { stoff nach Buns en } \\
\text { im ausgefällten } \\
\text { Harn in } \% \text { be- } \\
\text { rechnet nach der } \\
\text { Bestimmung von }\end{array}$} & \multirow[t]{2}{*}{$\begin{array}{c}\text { Fehler der } \\
\text { Methode von } \\
\text { Bunsen }\end{array}$} & \multirow{2}{*}{$\begin{array}{c}\text { Wie viel } \\
\text { Stickstoff } \\
\text { nicht in } \\
\text { Aarnstoff, } \\
\text { wenn Ge- } \\
\text { sammtstick- } \\
\text { stoff }=100\end{array}$} \\
\hline & $\mathrm{NH}_{3}$ & $\mathrm{CO}_{2}$ & $\mathrm{NH}_{3}$ & $\mathrm{CO}_{2}$ & & \\
\hline 1,178 & 1,120 & 1,131 & 1,060 & 1,088 & $+8,96$ & 11,9 \\
\hline
\end{tabular}

Tabelle für Versuchsserie IV.

Versuchsserie V.

Harn IV.

I. Gesammtstickstoff.

Je $5 \mathrm{ccm}$ Harn mit $40 \mathrm{ccm}$ ranchender Schwefelsäure 10 Stunden gekocht.

Vorlage: $66 \mathrm{ccm} 1 / 10 \mathrm{SO}_{4} \mathrm{H}_{2}$ :

1/10 Hyposulfitlösung $=10,19 \mathrm{ccm}$ und $10,13 \mathrm{ccm}$ entsprechend: $0,07836 \mathrm{gr}$ und $0,7844 \mathrm{gr}$ Stickstoff.

Mittel: $0,07840 \mathrm{gr}$ Stickstoff.

Harn enthält also: $1,568 \%$ Stickstoff in toto.

II. Harnbestimmung nach Bunsen ohne Ausfällung der Extractivstoffe.

1. $30 \mathrm{ccm}$ Harn auf $100 \mathrm{ccm}$ verdünnt; $50 \mathrm{ccm}$ der Mischung mit $50 \mathrm{ccm}$ alkalischer $\mathrm{BaCl}_{2}$-Lösung versetzt und vom Filtrat je $15 \mathrm{ccm}=2,25 \mathrm{ccm}$ Harn eingeschmolzen. Alkalescenz für diese $15 \mathrm{ccm}=12,0 \mathrm{~cm} 1 / 10$ Alkali.

2. a) Ammoniakbestimmung.

Vorlage: $30 \mathrm{ccm} 1 / 10 \quad \mathrm{SO}_{4} \mathrm{H}_{2}$.

Rohr I. Mit Natronlange destillirt:

1/10 Hyposulfitlösung $=6,65 \mathrm{ccm}: 0,03278 \mathrm{gr}$ Stickstofi. 
Rohr II. Mit $\mathrm{MgO}$ destillirt:

1/10 Hyposulfitlösung $=6,43 \mathrm{ccm}: 0,03309 \mathrm{gr}$ Stickstoff.

Mittel $=0,03294 \mathrm{gr}$ Stickstoff.

Also $5 \mathrm{ccm}$ Harn $=0,07319 \mathrm{gr}$ Stickstoff;

Harn enthält: $1,464 \%$ Stickstoff in Harnstoff.

b) Kohlensäurebestimmung.

Rohr III.

Hgu $=65,57$
Hgo $=35,49$$\quad$ Kaliber $\begin{cases}35 \mathrm{~cm}=75 \mathrm{ccm} & \mathrm{T}=10,6^{0} \mathrm{C} . \\ 1 \mathrm{~cm}=2,14 \mathrm{cem} & \mathrm{Ba}=762,5 .\end{cases}$

$\mathrm{V}=76,26 \mathrm{ccm} ; \mathrm{P}=451,32 \mathrm{~mm}$.

Reducirtes Gesammtgas $=43,59 \mathrm{ccm}$.

Nach Absorption der Kohlensäure:

$\begin{aligned} \mathrm{Hgu} & =65,79 \\ \mathrm{HgO} & =21,56 \\ \mathrm{KOH} & =20,00\end{aligned} \quad$ Kaliber $\begin{cases}21,05 \mathrm{~cm}=45 \mathrm{~cm} & \mathrm{~T} 10,8^{\circ} \mathrm{C} . \\ 1 \mathrm{~cm}=2,128 \mathrm{~cm} & \mathrm{Ba} 764,5 \mathrm{~mm} .\end{cases}$

Reducirtes restirendes Gas $=17,10 \mathrm{ccm}$.

Folglich: $26,493 \mathrm{com} \mathrm{CO} \mathrm{CO}_{2}=52,10 \mathrm{mgr} \quad \mathrm{CO}_{2}=71,05 \mathrm{mgr} \stackrel{+}{\mathrm{U}}=0,03316 \mathrm{gr}$ Stickstoff.

Rohr IV.

Hgu $=64,25$
Hgo $=33,90$$\quad$ Kaliber $\left\{\begin{array}{l}33,98 \mathrm{~cm}=72 \mathrm{ccm} \\ 1 \mathrm{~cm}=2,11 \mathrm{ccm}\end{array} \quad \begin{array}{c}\mathrm{Ta}=10,6^{0} \mathrm{C} . \\ \mathrm{Ba}=762,5 \mathrm{~mm} .\end{array}\right.$

$\mathrm{V}=72,04 \mathrm{ccm} ; \mathrm{P}=448,62 \mathrm{~mm}$.

Reducirtes Gesammtgas $=40,93 \mathrm{ccm}$.

Nach Absorption der Kohlensäure:

Hgu $=64,47$
Hgo $=19,20$
KOH $=17,66$$\quad$ Kaliber $\begin{cases}16,99 \mathrm{~cm}=36 \mathrm{~cm} & \mathrm{~T}=10,8^{\circ} \mathrm{C} . \\ 1 \mathrm{~cm}=2,112 \mathrm{~cm} & \mathrm{Ba}=764,5 .\end{cases}$

$\mathrm{V}=37,42 \mathrm{ccm} ; \quad \mathrm{P}=305,63 \mathrm{~mm}$.

Reducirtes restirendes Gas $=14,476 \mathrm{ccm}$. Stickstoff.

Folglich: $26,45 \mathrm{ccm} \quad \mathrm{CO}_{2}=52,02 \mathrm{mgr} \mathrm{CO}_{\mathrm{g}}=70,93 \mathrm{mgr} \stackrel{+}{\mathrm{U}}=0,03310 \mathrm{gr}$

Mittel: $0,03314 \mathrm{gr}$ Stickstoff.

$5 \mathrm{ccm}$ Harn also $=0,07364 \mathrm{gr}$ Stickstoff.

Der Harn enthält: 1,473\% Stickstoff in Harnstoff.

III. Harnstoffbestimmung nach Bunsen nach Elimination der durch Phosphorwolframsäure fällbaren "Extractivstoffe".

200,1 ccm Harn

20,0 "Salzsäure

150,0 "Phosphorwolframsäure

$370,1 \mathrm{ccm}$ Mischung. 
1. Volum des entstandenen Niederschlages $=2,2 \mathrm{ccm}$. $-200,21 \mathrm{ccm}$ des Filtrats $=108,894$ Harn mit Kalkpulver $\left(\mathrm{Ca}(\mathrm{OH})_{2}\right)$ alkalisch gemacht; das Filtrat mit gleichem Volum alkalischer $\mathrm{Cl}_{2} \mathrm{Ba}$-Lösung versetzt und von diesem Filtrat je $15 \mathrm{~cm}=4,0793 \mathrm{~cm}$ Harn eingesehmolzen. Bei der Ausfällung mit $\mathrm{Ca}(\mathrm{OH})_{2}$ hatte die Expansion 4,32 ccm betragen, das Volum des Niederschlags ebenfalls $4,32 \mathrm{ccm}$.

2. a) Ammoniakbestimmung.

$$
\text { Vorlage } 50 \mathrm{ccm} 1 / 10 \mathrm{SO}_{4} \mathrm{H}_{2} \text { : }
$$

Rohr I. Mit Natronlauge destillirt:

1/10 Hyposulftiösung $=10,15 \mathrm{ccm}: 0,05595 \mathrm{gr}$ Stickstoff.

Rohr II. Mit MgO destillirt:

1/10 Hyposulfitlösung $=10,28 \mathrm{ccm}: 0,05577 \mathrm{gr}$ Stickstoff.

$$
\text { Mittel }=0,05586 \mathrm{gr} \text { Stickstoff. }
$$

$5 \mathrm{ccm}$ Harn also $=0,06847 \mathrm{gr}$ Stickstoff.

Harn enthält also $=1,369 \%$ Stickstoff in Harnstoff.

b) Kohlensäurebestimmung.

Rohr III.

Hgu $=66,15$
Hgo $=43,39$$\quad$ Kaliber $\begin{cases}43,25 \mathrm{~cm}=93 \mathrm{~cm} & \mathrm{~T}=13,7^{0} \mathrm{C} . \\ 1 \mathrm{~cm}=2,158 \mathrm{ccm} & \mathrm{Ba}=758,6 \mathrm{~mm} .\end{cases}$

$\mathrm{V}=93,518 \mathrm{ccm} ; \quad \mathrm{P}=518,08 \mathrm{~mm}$.

Reducirtes Gesammtgas $=60,71 \mathrm{ccm}$.

Nach Absorption der Kohlensäure:

$$
\begin{aligned}
& \mathrm{Hgu}=66,45 \\
& \text { Hgo }=22,85 \\
& \mathrm{KOH}=20,40 \\
& \text { Kaliber }\left\{\begin{aligned}
21,05 \mathrm{~cm} & =45 \mathrm{ccm} \\
1 \mathrm{~cm} & =2,128 \mathrm{ccm} \quad \mathrm{Ba}=13,5^{0} \mathrm{C} .
\end{aligned}\right. \\
& V=43,62 \mathrm{ccm} ; \quad P=315,95 \mathrm{~mm} \text {. } \\
& \text { Reducirtes restirendes Gas }=17,282 \mathrm{ccm} \text {. }
\end{aligned}
$$

Folglich $43,43 \mathrm{~cm} \mathrm{CO} \mathrm{CO}_{2}=85,41 \mathrm{mgr} \mathrm{CO} 2=116,47 \mathrm{mgr} \stackrel{+}{\mathrm{U}}=0,05435 \mathrm{gr}$ Stickstoff.

Rohr IV.

$$
\begin{aligned}
& \begin{array}{l}
\mathrm{Hgu}=64,67 \\
\mathrm{Hgo}=45,45
\end{array} \quad \text { Kaliber }\left\{\begin{array}{l}
45,1 \mathrm{~cm}=96 \mathrm{~cm} \\
1 \mathrm{~cm}=2,158 \mathrm{ccm} \quad \mathrm{Ba}=13,7^{0} \mathrm{C} .
\end{array}\right. \\
& \mathrm{V}=96,971 \mathrm{ccm} ; \quad \mathrm{P}=553,39 \mathrm{~mm} \text {. } \\
& \text { Reducirtes Gesammtgas }=67,24 \mathrm{ccm} \text {. }
\end{aligned}
$$

Nach Absorption der Kohlensäure:

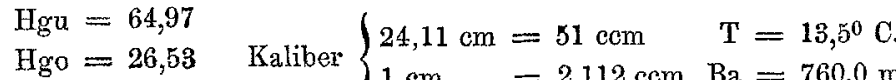

$$
\begin{aligned}
& \mathrm{KOH}=24,42 \quad\{1 \mathrm{~cm}=2,112 \mathrm{ccm} \mathrm{Ba}=760,0 \mathrm{~mm} \text {. } \\
& \mathrm{V}=51,65 \mathrm{ccm} ; \quad \mathrm{P}=367,79 \mathrm{~mm} \text {. } \\
& \text { Reducirtes restirendes Gas }=23,818 \mathrm{ccm} \text {. }
\end{aligned}
$$

Folglich $43,424 \mathrm{ccm} \mathrm{CO}_{2}=85,398 \mathrm{mgr} \mathrm{CO} \mathrm{CO}_{2}=116,45 \mathrm{mgr} \stackrel{+}{\mathrm{U}}=0,054344 \mathrm{gr}$ Stickstoff. 
Mittel $=0,054345 \mathrm{gr}$ Stickstoff.

$5 \mathrm{ccm}$ Harn $=0,06661 \mathrm{gr}$ Stickstoff.

Der Harn enthält also 1,332\% Stickstoff in Harnstoff.

Tabelle für Versuchsserie V.

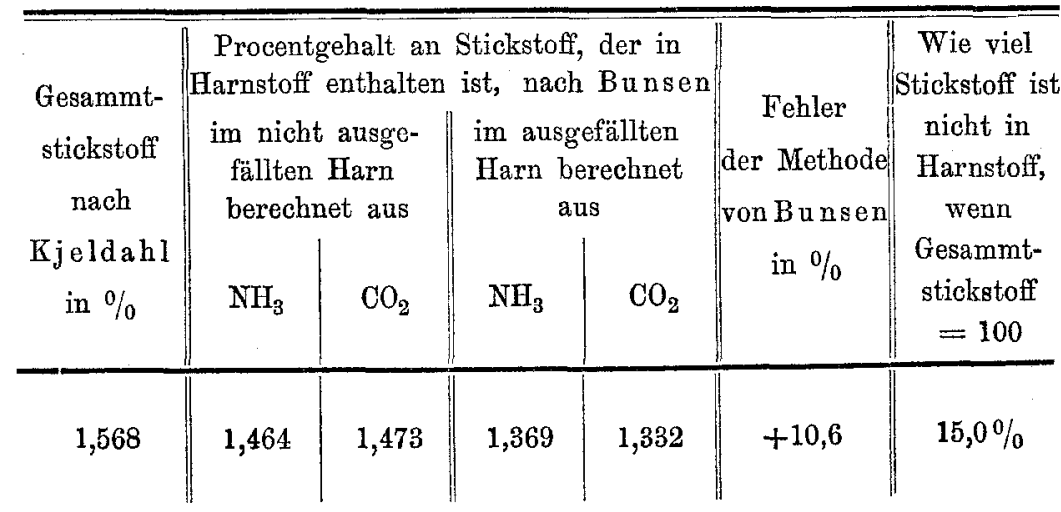

\section{Versuchsserie VI.}

\section{Harn III.}

I. Gesammtstickstoff.

Je $5 \mathrm{ccm}$ Harn mit $40 \mathrm{ccm}$ rauchender Schwefelsäure 10 Stunden gekocht. Vorlage $47 \mathrm{ecm} 1 / 10 \mathrm{SO}_{4} \mathrm{H}_{2}$.

1/10 Hyposulfitlösung $=11,75 \mathrm{ccm}$ und $11,82 \mathrm{ccm}$,

entsprechend: $0,04949 \mathrm{gr}$ und $0,04939 \mathrm{gr}$ Stickstoff.

Mittel $=0,04944 \mathrm{gr}$ Stickstoff.

Harn enthält also: $0,989 \%$ Stickstoff in toto.

II. Harnstoffbestimmung nach Bunsen ohne Ausfällung der Extractivstoffe.

1. $40 \mathrm{ccm}$ Harn auf $100 \mathrm{ccm}$ verdünnt; $50 \mathrm{ccm}$ dieser Mischung mit $50 \mathrm{ccm}$ alkalischer $\mathrm{Ba} \mathrm{Cl}_{2}$-Lösung versetzt und vom Filtrat je $15 \mathrm{ccm}=3 \mathrm{ccm}$ Harn eingeschmolzen. Alkalescenz für diese $15 \mathrm{ccm}=13,5 \mathrm{ccm} \mathrm{1/10}$ Alkali.

2. a) Ammoniakbestimmung. Vorlage $30 \mathrm{ccm} 1 / 10 \mathrm{SO}_{4} \mathrm{H}_{2}$.

Rohr I. Mit Natronlauge destillirt:

$1 / 10$ Hyposulfitiösung $=10,08 \mathrm{ccm}: 0,02797 \mathrm{gr}$ Stickstoff

Rohr II. Mit $\mathrm{MgO}$ destillirt:

1/10 Hyposulfitlösung $=9,9 \mathrm{ccm}: 0,02822$, ,

$$
\text { Mittel }=0,02809 \mathrm{gr} \text { Stickstoff. }
$$

$5 \mathrm{ccm}$ Harn enthalten also: 0,04682 gr Stickstoff.

Der Harn enthält: $0,936 \%$ Stickstoff in Harnstoff. 
b) Kohlensäurebestimmung.

Rohr III.

$$
\begin{gathered}
\text { Hgu }=64,26 \quad \text { Kaliber }\left\{\begin{array}{l}
33,98 \mathrm{~cm}=72 \mathrm{~cm} \\
1 \mathrm{~cm}=2,19 \mathrm{~cm}
\end{array} \quad \mathrm{Ta}=13,2^{\circ} \mathrm{C} .\right. \\
\text { Hgo }=34,09,6 \mathrm{~mm} . \\
\mathrm{V}=72,460 \mathrm{ccm} ; \mathrm{P}=445,54 \mathrm{~mm} .
\end{gathered}
$$

Nach Absorption der Kohlensäure:

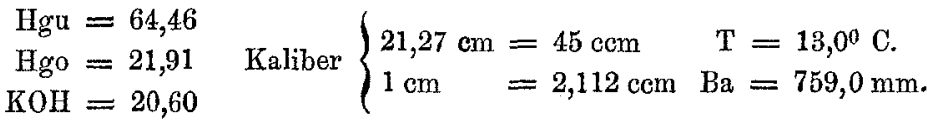

$$
\begin{aligned}
& \mathrm{V}=43,585 \mathrm{ccm} ; \quad \mathrm{P}=326,76 \mathrm{~mm} \text {. } \\
& \text { Reducirtes restirendes Gas }=17,888 \mathrm{ccm} \text {. }
\end{aligned}
$$

Folglich $22,634 \mathrm{ccm} \mathrm{CO}_{2}=44,512 \mathrm{mgr} \quad \mathrm{CO}_{2}=60,7 \mathrm{mgr} \stackrel{+}{\mathrm{U}}=0,02832 \mathrm{gr}$ Stickstoff.

Rohr IV.

$$
\begin{gathered}
\text { Hgu }=65,08 \quad \text { Kaliber }\left\{\begin{array}{l}
33,6 \mathrm{~cm}=72 \mathrm{~cm} \quad \mathrm{~T}=13,20 \mathrm{c} . \\
1 \mathrm{~cm}=2,142 \mathrm{~cm} \mathrm{Ba}=759,6 \mathrm{~mm}
\end{array}\right. \\
\text { Hgo }=33,76 \quad \mathrm{ca}=72,557 \mathrm{ccm} ; \quad \mathrm{P}=434,09 \mathrm{~mm} . \\
\text { Reducirtes Gesammtgas }=39,534 \mathrm{ccm} .
\end{gathered}
$$

Nach Absorption der Kohlensäure:

$$
\begin{gathered}
\text { Hgu }=65,29 \\
\text { Hgo }=21,66 \quad \text { Kaliber }\left\{\begin{array}{l}
19,64 \mathrm{~cm}=42 \mathrm{~cm} \quad \mathrm{~T}=13,0^{0} \mathrm{C} . \\
1 \mathrm{~cm}=2,128 \mathrm{~cm} \mathrm{Ba}=759,0 \mathrm{~mm} .
\end{array}\right. \\
\mathrm{KOH}=19,70 \\
\mathrm{~V}=42,128 \mathrm{~cm} ; \mathrm{P}=315,32 \mathrm{~mm} . \\
\text { Reducirtes restirendes Gas }=16,686 \mathrm{ccm} .
\end{gathered}
$$

Folglich $22,848 \mathrm{~cm} \mathrm{CO} \mathrm{CO}_{2}=44,933 \mathrm{mgr} \mathrm{CO} \mathrm{CO}_{2}=61,27 \mathrm{mgr} \stackrel{+}{\mathrm{U}}=0,02859 \mathrm{gr}$ Stickstoff.

$$
\begin{aligned}
\text { Mittel } & =0,02845 \mathrm{gr} \text { Stickstoff. } \\
5 \mathrm{ccm} \text { Harn } & =0,04742 \mathrm{gr} \text { Stickstoff. } \\
\text { Harn enthält } & =0,948 \% \text { Stickstoff in Harnstoff. }
\end{aligned}
$$

III. Harnstoffbestimmung nach Bunsen nach Elimination an durch Phosphorwolframsäure fällbaren ,Extractivstoffe".

1.

$$
\begin{aligned}
& 200,21 \mathrm{ccm} \text { Harn } \\
& 20,00 \% \text { Salzsäure } \\
& 120,00 \% \text { Phosphorwolframsäure } \\
& 340,21 \mathrm{~cm} \text { Mischung. }
\end{aligned}
$$

Volum des entstandenen Niederschlags $=1,4 \mathrm{ccm} .-200,1 \mathrm{ccm}$ des Filtrats $=118,243 \mathrm{~cm}$ Harn mit Kalkpulver $\left(\mathrm{Ca}(\mathrm{OH})_{2}\right)$ alkalisch gemacht; das Filtrat mit gleichem Volum alkalischer $\mathrm{BaCl}_{2}$-Lösung versetzt und filtrirt. Je $15 \mathrm{ccm}=4,412 \mathrm{ccm}$ Harn eingeschmolzen. Expansion bei Ausfällung mit 
$\mathrm{Ca}(\mathrm{OH})_{2}$ betrug $4,87 \mathrm{ccm}$; Volum des entstandenen Niederschlags $3,97 \mathrm{ccm}$; folglich ein Plus an Fixpansion von 0,9 ccm.

2. a) Ammoniakbestimmung.

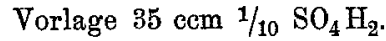

Rohr I. Mit Natronlauge destillirt:

$1 / 10$ Hyposulfitlösung $=7,0 \mathrm{ccm}: 0,03931 \mathrm{gr}$ Stickstoff,

Rohr II. Mit MgO destillirt:

1/10 Hyposulfitlösung $=7,4 \mathrm{ccm}: 0,03875, \quad "$

Mittel: $0,03903 \mathrm{gr}$ Stickstoff.

$5 \mathrm{ccm}$ Harn $=0,04423 \mathrm{gr}$ Stickstoff.

Harn enthält $=0,885 \%$ Stickstoff in Harnstoff.

b) Kohlensäurebestimmung.

Rohr III.

$$
\begin{aligned}
& \begin{array}{l}
\text { Hgu }=65,49 \\
\text { Hgo }=36,40
\end{array} \quad \text { Kaliber }\left\{36,4 \mathrm{~cm}=78 \mathrm{ccm} \quad \begin{array}{rl}
\mathrm{T} & =14,0^{\circ} \mathrm{C} . \\
\mathrm{Ba} & =760,6 \mathrm{~mm} .
\end{array}\right. \\
& \mathrm{V}=78,216 \mathrm{~cm} ; \quad \mathrm{P}=456,67 \mathrm{~mm} \text {. } \\
& \text { Reducirtes Gesammtgas }=44,708 \mathrm{ccm} \text {. }
\end{aligned}
$$

Nach Absorption der Kohlensäure:

$$
\begin{aligned}
& \begin{aligned}
\mathrm{Hgu} & =65,76 \\
\mathrm{Hgo} & =20,11 \\
\mathrm{KOH} & =18,33
\end{aligned} \quad \text { Kaliber }\left\{\begin{array}{l}
18,25 \mathrm{~cm}=39 \mathrm{~cm} \quad \mathrm{~T}=13,9^{\circ} \mathrm{C} . \\
1 \mathrm{~cm}=2,158 \mathrm{ccm} \quad \mathrm{Ba}=762,0 \mathrm{~mm} .
\end{array}\right. \\
& \mathrm{V}=39,17 \mathrm{ccm} ; \quad P=298,03 \mathrm{~mm} \text {. } \\
& \text { Reducirtes restirendes Gas }=14,617 \mathrm{~cm} \text {. }
\end{aligned}
$$

Folglich $30,09 \mathrm{ccm} \mathrm{CO}_{2}=59,18 \mathrm{mgr} \quad \mathrm{CO}_{2}=80,70 \mathrm{mgr} \stackrel{+}{\mathrm{U}}=0,03766 \mathrm{gr}$ Stickstoff.

Rohr IV.

$$
\begin{aligned}
& \mathrm{Hgu}=64,05 \\
& \mathrm{Hgo}=35,50 \quad \text { Kaliber }\left\{\begin{array}{l}
35,35 \mathrm{~cm}=75 \mathrm{~cm} \quad \mathrm{~T}=14,0^{\circ} \mathrm{C} . \\
1 \mathrm{~cm}=2,143 \mathrm{~cm} \mathrm{Ba}=760,6 \mathrm{~mm} .
\end{array}\right. \\
& \mathrm{V}=75,536 \mathrm{ccm} ; \mathrm{P}=462,06 \mathrm{~mm} . \\
& \text { Reducirtes Gesammtgas }=43,685 \mathrm{~cm} .
\end{aligned}
$$

$$
\begin{gathered}
\mathrm{Hgu}=64,31 \\
\mathrm{Hgo}=19,05 \quad \text { Kaliber }\left\{\begin{array}{l}
16,99 \mathrm{~cm}=36 \mathrm{~cm} \quad \mathrm{~T}=13,9^{\circ} \mathrm{c} . \\
1 \mathrm{~cm}=2,112 \mathrm{~cm} \mathrm{Ba}=762,0 \mathrm{~mm} .
\end{array}\right. \\
\mathrm{KOH}=17,16 \\
\mathrm{~V}=36,359 \mathrm{ccm} ; \mathrm{P}=301,8 \mathrm{~mm} .
\end{gathered}
$$

Stickstoff.

Folglich $29,95 \mathrm{ccm} \mathrm{CO}_{2}=58,90 \mathrm{mgr} \mathrm{CO}_{2}=80,32 \mathrm{mgr} \stackrel{+}{\mathrm{U}}=0,03748 \mathrm{gr}$

$$
\begin{aligned}
\text { Mittel } & =0,03757 \mathrm{gr} \text { Stickstoff. } \\
5 \mathrm{ccm} \text { Harn } & =0,04257 \mathrm{gr} \text { Stickstoff. }
\end{aligned}
$$

Der Harn enthält: $0,851 \%$ Stickstoff in Harnstoff. 
Tabelle für Versuchsserie VI.

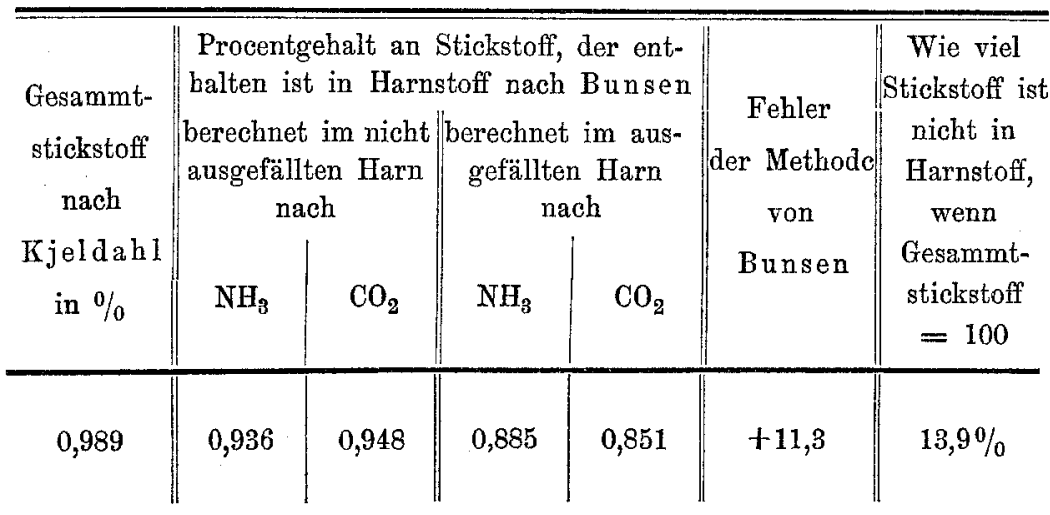

Versuchsserie VII.

Harn VII.

I. Gesammtstickstoff.

Je $5 \mathrm{ccm}$ Harn mit $40 \mathrm{ccm}$ rauchender Schwefelsäure 10 Stunden gekocht. Vorlage $34 \mathrm{ccm} 1 / 10 \quad \mathrm{SO}_{4} \mathrm{H}_{2}$.

$1 / 10$ Hyposulfitlösung $=9,9 \mathrm{ccm}$ und $9,98 \mathrm{ccm}$, entsprechend: $0,03384 \mathrm{gr}$ und $0,03372 \mathrm{gr}$ Stickstoff;

Mittel $=0,03378 \mathrm{gr}$ Stickstoff.

Harn $=0,676 \%$ Stickstoff in toto.

II. Harnstoffbestimmung nach Bunsen ohne Elimination der durch Phosphorwolframsäure fällbaren Extractivstoffe.

1. $60 \mathrm{ccm}$ Harn auf $100 \mathrm{ccm}$ verdünnt; $50 \mathrm{ccm}$ dieser Mischung mit $50 \mathrm{ccm}$ alkalischer $\mathrm{BaCl}_{2}$-Lösung versetzt und je $15 \mathrm{ccm}$ des Filtrats $=4,5 \mathrm{ccm}$ Harn eingeschmolzen. Alkalescenz für diese $15 \mathrm{ccm}=13,5 \mathrm{~cm} 1 / 10$ Alkali.

2. a) Ammoniakbestimmung.

Vorlage $30 \mathrm{ccm} 1 / 10 \mathrm{SO}_{4} \mathrm{H}_{2}$.

Rohr I. Mit Natronlauge destillirt:

$1 / 10$ Hyposulfitlösung $=9,9 \mathrm{ccm}: 0,02822 \mathrm{gr}$ Stickstoff.

Rohr II. Mit $\mathrm{Mg} \mathrm{O}$ destillirt:

$1 / 10$ Hyposulfitlösung $=9,9 \mathrm{ccm}: 0,02822$, "

$$
\text { Mittel }=0,02822 \text { gr Stickstoff. }
$$

$5 \mathrm{ccm}$ Harn $=0,03136 \mathrm{gr}$ Stickstoff.

Harn enthält: $0,627 \%$ Stickstoff in Harnstoff. 
b) Kohlensäurebestimmung.

Rohr III.

$$
\begin{gathered}
\mathrm{Hgu}=66,31 \\
\mathrm{Hgo}=33,34 \quad \text { Kaliber }\left\{\begin{array}{l}
33,60 \mathrm{~cm}=72 \mathrm{~cm} \quad \mathrm{~T}=13,7^{\circ} \mathrm{C} . \\
1 \mathrm{~cm}=2,206 \mathrm{~cm} \quad \mathrm{Ba}=762,8 \mathrm{~mm} . \\
\mathrm{V}=71,65 \mathrm{~cm} ; \quad \mathrm{P}=420,42 \mathrm{~mm} .
\end{array}\right. \\
\text { Reducirtes Gesammtgas }=37,743 \mathrm{~cm} .
\end{gathered}
$$

Nach Absorption der Kohlensäure:

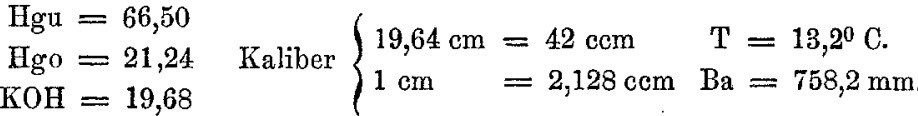

$$
\begin{aligned}
& \mathrm{V}=42,085 \mathrm{ccm} ; \mathrm{P}=298,61 \mathrm{~mm} \text {. } \\
& \text { Reducirtes restirendes } \mathrm{Gas}=15,773 \mathrm{~cm} \text {. }
\end{aligned}
$$

Folglich $21,97 \mathrm{ccm} \mathrm{CO} 2=43,206 \mathrm{mgr} \mathrm{CO}_{2}=58,917 \mathrm{mgr} \stackrel{+}{\mathrm{U}}=0,02750 \mathrm{gr}$ Stickstoff.

Rohr IV.

$$
\begin{aligned}
& \begin{array}{l}
\text { Hgu }=64,94 \\
\text { Hgo }=32,88
\end{array} \text { Kaliber }\left\{\begin{array}{l}
32,56 \mathrm{~cm}=69 \mathrm{~cm} \quad \mathrm{~T}=13,7^{0} \mathrm{C} . \\
1 \mathrm{~cm}=2,112 \mathrm{ccm} \quad \mathrm{Ba}=762,8 \mathrm{~mm}
\end{array}\right. \\
& \mathrm{V}=69,887 \mathrm{ccm} ; \quad \mathrm{P}=429,5 \mathrm{~mm} \text {. } \\
& \text { Reducirtes Gesammtgas }=37,609 \mathrm{ccm} \text {. }
\end{aligned}
$$

Nach Absorption der Kohlensäure:

$$
\begin{aligned}
& \mathrm{Hgu}=65,14 \\
& \text { Hgo }=20,35 \\
& \mathrm{KOH}=18,85 \\
& \text { Kaliber }\left\{\begin{array}{rlrl}
19,85 \mathrm{~cm} & =42 \mathrm{~cm} & \mathrm{~T} & =13,2^{\circ} \mathrm{C} . \\
1 \mathrm{~cm} & =2,08 \mathrm{~cm} & \mathrm{Ba} & =758,2 \mathrm{~mm} .
\end{array}\right. \\
& \mathrm{V}=39,92 \mathrm{ccm} ; \quad \mathrm{P}=303,35 \mathrm{~mm} \text {. }
\end{aligned}
$$

Reducirtes restirendes Gas $=15,199 \mathrm{ccm}$.

Folglich 22,41 $\mathrm{ccm} \mathrm{CO} 0_{2}=44,069 \mathrm{mgr} \mathrm{CO}_{2}=60,094 \mathrm{mgr} \stackrel{+}{\mathrm{U}}=0,02804 \mathrm{gr}$ Stickstoff.

$$
\begin{aligned}
\text { Mittel } & =0,02777 \mathrm{gr} \text { Stickstoff. } \\
5 \mathrm{ccm} \text { Harn } & =0,03086 \mathrm{gr} \text { Stickstoff. } \\
\text { Harn enthält : } & 0,617 \% \text { Stickstoff in Harnstoff. }
\end{aligned}
$$

III. Harnstoffbestimmang nach Bunsen nach Elimination der durch Phosphorwolframsäure fällbaren "Extractivstoffe".

1.

$$
\begin{aligned}
& 200,29 \text { ccm } \text { Harn } \\
& 20,00 \text { Salzsäure } \\
& 80,00 \quad \text { " Phorphorwolframsäure }
\end{aligned}
$$

$300,29 \mathrm{ccm}$ Mischung.

Volum des entstandenen Niederschlags $0,35 \mathrm{ccm}$.

$200,29 \mathrm{ccm}$ des Filtrates $=133,745 \mathrm{ccm}$ Harn mit Kalkpulver $\left[\mathrm{Ca}(\mathrm{OH})_{2}\right]$ alkalisch gemacht; das Filtrat mit gleichem Volum alkalischer $\mathrm{BaCl}_{2}$-Lösung versetzt und filtrirt; von dieser Mischung jo $15 \mathrm{ccm}=4,971 \mathrm{ccm}$ Harn ein- 
geschmolzen. Die Expansion bei der Ausfällung mit $\mathrm{Ca}(\mathrm{OH})_{2}$ hatte betragen $3,00 \mathrm{ccm}$; das Volum des entstandenen Niederschlages $1,5 \mathrm{ccm}$, so dass ein Plus an Expansion von $1,5 \mathrm{ccm}$ bleibt.

2. a) Ammoniakbestimmung.

Vorlage $30 \mathrm{ccm} 1 / 10 \mathrm{SO}_{4} \mathrm{H}_{2}$.

Rojr I. Mit Natronlauge destillirt:

1/10 Hyposulfitlösung $=8,6 \mathrm{ccm}: 0,03005 \mathrm{gr}$ Stickstof,

Rohr II. Mit MgO destillirt:

$1 / 10$ Hyposulfitlösung $=8,36 \mathrm{ccm}: 0,03038$ "

Mittel $=0,03026 \mathrm{gr}$ Stickstoff.

$5 \mathrm{ccm}$ Harn $=0,08044 \mathrm{gr}$ Stickstoff.

Harn enthält: $0,609 \%$ Stickstoff in Harnstoff.

b) Kohlensäurebestimmung.

Rohr III.

$\mathrm{Hgu}=66,70$
$\mathrm{Hgo}=34,35$ Kaliber $\left\{\begin{array}{l}33,60 \mathrm{~cm}=72 \mathrm{~cm} \\ 1 \mathrm{~cm}=2,142 \mathrm{ccm} \quad \mathrm{Ba}=759,5 \mathrm{~mm} .\end{array}\right.$

$\mathrm{V}=73,82 \mathrm{ccm} ; \quad \mathrm{P}=422,10 \mathrm{~mm}$.

Reducirtes Gesammtgas $=38,852 \mathrm{ccm}$.

Nach Absorption der Kohlensäure:

$$
\begin{aligned}
\text { Hgu } & =66,80 \\
\mathrm{HgO} & =20,76 \\
\mathrm{KOH} & =19,40
\end{aligned} \quad \text { Kaliber }\left\{\begin{array}{l}
19,64 \mathrm{~cm}=42 \mathrm{~cm} \\
1 \mathrm{~cm}=2,158 \mathrm{ccm} \quad \mathrm{Ba}=759,5 \mathrm{~mm} .
\end{array}\right.
$$

$\mathrm{V}=4.1,48 \mathrm{~cm} ; \quad \mathrm{P}=291,41 \mathrm{~mm}$.

Reducirtes restirendes Gas $=15,046 \mathrm{ccm}$.

Folglich $23,806 \mathrm{ccm} \mathrm{CO}_{2}=46,817 \mathrm{mgr} \mathrm{CO}_{2}=63,84 \mathrm{mgr} \stackrel{+}{\mathrm{U}}=0,02979 \mathrm{gr}$ Stickstoff.

Rohr IV.

$$
\begin{aligned}
& \begin{array}{l}
\text { Hgu }=64,94 \\
\text { Hgo }=37,00
\end{array} \text { Kaliber }\left\{\begin{array}{l}
36,75 \mathrm{~cm}=78 \mathrm{~cm} \quad \mathrm{~T}=14,4^{0} \mathrm{C} . \\
1 \mathrm{~cm}=2,143 \mathrm{~cm} \quad \mathrm{Ba}=747,8 \mathrm{~mm} .
\end{array}\right. \\
& \mathrm{V}=78,75 \mathrm{~cm} ; \quad \mathrm{P}=455,03 \mathrm{~mm} \text {. }
\end{aligned}
$$

Nach Absorption der Kohlensäure:

$$
\begin{aligned}
& \begin{aligned}
\text { Hga }=65,13 \\
\text { Hgo }=24,34 \\
\mathrm{KOH}=23,30
\end{aligned} \quad \text { Kaliber }\left\{\begin{array}{l}
24,11 \mathrm{~cm}=51 \mathrm{ccm} \quad \mathrm{T}=13,6^{\circ} \mathrm{C} . \\
1 \mathrm{~cm}=2,128 \mathrm{ccm} \quad \mathrm{Ba}=750,7 \mathrm{~mm} .
\end{array}\right. \\
& V=49,276 \mathrm{~cm} ; \quad P=336,09 \mathrm{~mm} \text {. } \\
& \text { Reducirtes restirendes Gas }=20,758 \mathrm{ccm} \text {. }
\end{aligned}
$$

Folglich $24,032 \mathrm{ccm} \mathrm{CO} 2=47,262 \mathrm{mgr} \mathrm{CO} \mathrm{CO}_{2}=64,447 \mathrm{mgr} \stackrel{+}{\mathrm{U}}=0,03007 \mathrm{gr}$ Stickstoff.

$$
\text { Mittel }=0,02993 \mathrm{gr} \text { Stickstoff. }
$$

$5 \mathrm{ccm}$ Harn enthalten: 0,03014 gr Stickstoff in Harnstoff.

Der Harn enthält: $0,603 \%$ Stickstoff in Harnstoff. 
Tabelle zu Versuchsserie VII.

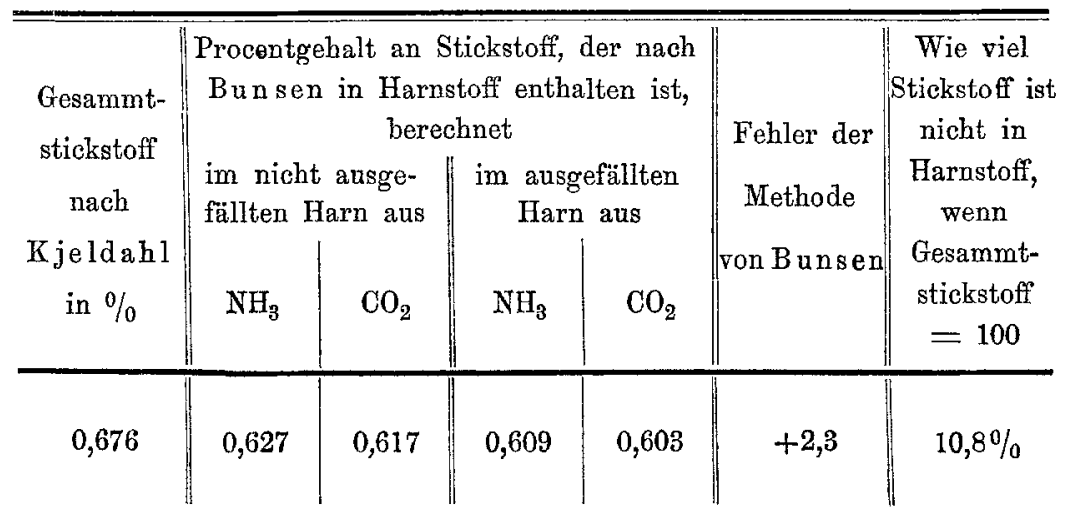

Versuchsserie VIII.

\section{Harn $\mathbf{X}$.}

\section{Gesammtstickstoff.}

Je $5 \mathrm{ccm}$ Harn mit $40 \mathrm{ccm}$ rauchender Schwefelsäure 10 Stunden gekocht. Vorlage $55 \mathrm{cem} 1 / 10 \quad \mathrm{SO}_{4} \mathrm{H}_{2}$.

$1 / 10$ Hyposulfitlösung $5,10 \mathrm{ccm}$ und $5,22 \mathrm{~cm}$, entsprechend: $0,07006 \mathrm{gr}$ und $0,06989 \mathrm{gr}$ Stickstoff.

Mittel: $0,06998 \mathrm{gr}$ Stickstoff.

Harn enthält $1,3996 \%$ Stickstoff in toto.

II. Harnstoffbestimmung nach Bunsen ohne Elimination der durch Phosphorwolframsäure fällbaren "Extractivstoffe".

1. $35 \mathrm{ccm}$ Harn auf $100 \mathrm{~cm}$ verdünnt; $50 \mathrm{ccm}$ der Mischung mit $50 \mathrm{ccm}$ alkalischer $\mathrm{Cl}_{2} \mathrm{Ba}$-lösung versetzt; vom Filtrat je $15 \mathrm{ccm}=2,625 \mathrm{ccm}$ Harn eingeschmolzen. Die Alkalescenz dieser $15 \mathrm{ccm}$ war $=12,0 \mathrm{~cm} 1 / 10$ Alkali.

2. a) Ammoniakbestimmung.

Vorlage $30 \mathrm{ccm} 1 / 10 \quad \mathrm{SO}_{4} \mathrm{H}_{2}$.

Rohr I. Mit MgO destillirt: 5,52 1/10 Hyposulfit entsprechend: $0,03437 \mathrm{gr}$ Stickstoff.

Rohr II. Mit Natronlauge destillirt

1/10 Hyposulfit: $5,4 \mathrm{ccm}$ entsprechend: $0,03454 \mathrm{gr}$ "

Mittel $=0,03445 \mathrm{gr}$ Stickstoff.

$5 \mathrm{ccm}$ Harn $=0,06563 \mathrm{gr}$ Stickstoff.

Der Harn enthält 1,313\% Stickstoff in Harnstoff.

E. Pflüger, Archiv f. Payaiologie. $B$ Bd. 
b) Kohlensäurebestimmung.

Rohr III.

$$
\begin{aligned}
& \mathrm{V}=74,56 \mathrm{~cm} ; \mathrm{P}=459,25 \mathrm{~mm} . \\
& \text { Reducirtes Gesammtgas }=42,755 .
\end{aligned}
$$

Nach Absorption der Kohlensäure:

$$
\begin{aligned}
& \mathrm{Hgu}=64,59 \\
& \mathrm{Hgo}=20,35 \quad \text { Kaliber }\left\{\begin{array}{l}
18,41 \mathrm{~cm}=39 \mathrm{~cm} \quad \mathrm{~T}=14,1^{\circ} \mathrm{C} . \\
1 \mathrm{~cm}=2,083 \mathrm{ccm} \quad \mathrm{Ba}=763,1 \mathrm{~mm} . \\
\mathrm{KOH}=18,90 \\
\mathrm{~V}=40,02 \mathrm{~cm} ; \mathrm{P}=313,44 \mathrm{~mm} . \\
\text { Reducirtes restirendes Gas }=15,695 .
\end{array}\right. \\
& \text { Folglich 27,06 ccm } \mathrm{CO}_{2}=53,216 \text { mgr CO}=72,567 \mathrm{mgr} \stackrel{+}{\mathrm{U}} \\
& =0,03386 \mathrm{gr} \text { Stickstoff. } \\
& \text { 5 ccm Harn }=0,06450 \mathrm{gr} \text { Stickstoff. } \\
& \text { Der Harn enthält } 1,290 \% \text { Stickstoff in Harnstoff. }
\end{aligned}
$$

III. Harnstoffbestimmung aach Bunsen nach Elimination der durch Phosphorwolframsäure fällbaren "Extractivstoffe."

1.

$$
\begin{aligned}
& 200,18 \mathrm{ccm} \text { Harn, } \\
& 20,00 " \text { Salzsäure, } \\
& 110,00 " \text { Phosphorwolframsäure, } \\
& 330,18 \mathrm{ccm} \text { Mischung. }
\end{aligned}
$$

Volum des entstandenen Niederschlages $=1,65 \mathrm{ccm} .200,18 \mathrm{ccm}$ des sauren Filtrates $=121,97 \mathrm{ccm}$ Harn mit Kalkpulver $\left[\mathrm{Ca}(\mathrm{OH})_{2}\right]$ alkalisch gemacht; das Filtrat mit gleichem Volum alkalischer $\mathrm{BaCl}_{2}$-lösung versetzt und filtrirt. Von dieser Nischung je $15 \mathrm{ccm}$ eingeschmolzen.

Die Expansion bei Ausfällung mit $\mathrm{Ca}(\mathrm{OH})_{2}$ betrug $\quad 3,52 \mathrm{ccm}$.

Das Volum des entstandenen Niederschlages betrug 3,30 "

Folglich bleibt ein Plus an Expansion $\quad=0,22 \quad n$

$15 \mathrm{ccm}$ der eingeschmolzenen Mischung also 4,575 ccm Harn.

2. a) Ammoniakbestimmung.

Vorlage $50 \mathrm{ccm} \mathrm{1/10} \mathrm{SO}_{4} \mathrm{H}_{2}$.

Rohr I. Mit MgO destillirt:

$1 / 10$ Hyposulfitlösung $=10,3 \mathrm{ccm}: 0,05574 \mathrm{gr}$ Stickstoff.

Rohr II. Mit Natronlauge destillirt:

1/10 Hyposulfitlösung $=10,2 \mathrm{ccm}: 0,05588 \mathrm{gr}$ Stickstoff.

Mittel $=0,05581 \mathrm{gr}$ Stickstoff.

5 ccm Harn $=0,06099$ gr Stickstoff.

Harn enthält $=1,220 \%$ Stickstoff in Harnstoff. 
b) Kohlensäurebestimmung:

Rohr III.

$$
\begin{aligned}
& \begin{array}{l}
\text { Hgu }=65,27 \\
\text { Hgo }=41,71
\end{array} \quad \text { Kaliber }\left\{\begin{array}{l}
40,95 \mathrm{~cm}=87 \mathrm{~cm} \quad \mathrm{~T}=16,0^{\circ} \mathrm{C} . \\
1 \mathrm{~cm}=2,206 \mathrm{~cm} \quad \mathrm{Ba}=757,5 \mathrm{~mm} .
\end{array}\right. \\
& \nabla=88,90 \mathrm{ccm} ; \mathrm{P}=506,94 \mathrm{~mm} \text {. } \\
& \text { Reducirtes Gesammtgas }=56,019 \mathrm{ccm} \text {. }
\end{aligned}
$$

Nach Absorption der Kohlensïure:

$$
\begin{gathered}
\mathrm{Hgu}=65,63 \\
\mathrm{Hgo}=18,71 \\
\mathrm{KOH}=17,44 \\
\mathrm{~V}=36,95 \mathrm{ccm} ; \mathrm{P}=283,53 . \\
\text { Reducirtes restirendes } \mathrm{Gas}=13,077 \mathrm{~cm} .
\end{gathered}
$$

Folglich $42,942 \mathrm{ccm} \mathrm{CO}_{2}=84,45 \mathrm{mgr} \quad \mathrm{CO}_{2}=115,15 \mathrm{mgr} \stackrel{+}{\mathrm{U}}$

$$
=0,0537 \text { gr Stickstoff. }
$$

Rohr IV.

$$
\begin{aligned}
& \mathrm{Hgu}=66,25 \\
& \mathrm{Hgo}=41,76
\end{aligned} \quad \text { Kaliber }\left\{\begin{array}{l}
41,89 \mathrm{~cm}=90 \mathrm{~cm} \quad \mathrm{~T}=16,0^{\circ} \mathrm{C} . \\
1 \mathrm{~cm}=2,158 \mathrm{ccm} \mathrm{Ba}=758,0 \mathrm{~mm} .
\end{array}\right.
$$

$\mathrm{V} 89,936 \mathrm{ccm} ; \mathrm{P}=498,15 \mathrm{~mm}$.

Reducirtes Gesammtgas $=55,689 \mathrm{ccm}$.

Nach Absorption der Kohlensäure:

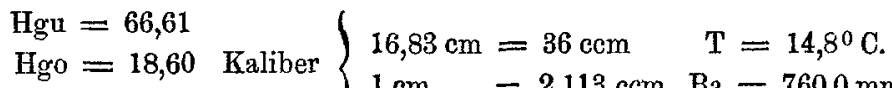

$$
\begin{aligned}
& \mathrm{KOH}=17,29 \quad\{1 \mathrm{~cm}=2,113 \mathrm{ccm} \mathrm{Ba}=760,0 \mathrm{~mm} \text {. } \\
& \mathrm{V}=36,97 \mathrm{ccm} ; \mathrm{P}=272,61 \mathrm{~mm} \text {. }
\end{aligned}
$$

Folglich : $43,11 \mathrm{ccm} \mathrm{CO} \mathrm{CO}_{2}=84,78 \mathrm{mgr} \mathrm{CO}=115,61 \mathrm{mgr} \stackrel{+}{\mathrm{U}}$

$$
=0,05395 \mathrm{gr} \text { Stickstoff. }
$$

Mittel: $0,05382 \mathrm{gr}$ Stickstoff.

$5 \mathrm{ccm}=0,0588 \mathrm{gr}$ Stickstoff.

Harn enthält 1,176\% Stickstoff in Harnstoff.

Tabelle zu Versuchsserie VIII.

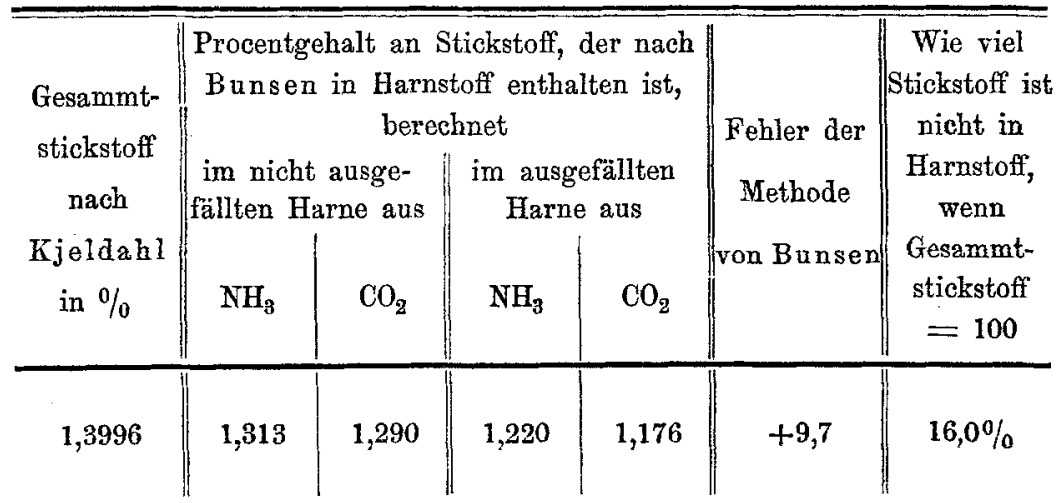


Generaltabelle.

Reagens zur Ausfällung der Extractivstoffe war Phosphorwolframsäure.

\begin{tabular}{|c|c|c|c|c|c|c|c|}
\hline \multirow{2}{*}{ 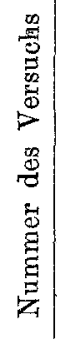 } & \multirow[t]{2}{*}{$\begin{array}{c}\text { Gesammt- } \\
\text { stickstoff } \\
\text { nach } \\
\text { Kjeldahl } \\
\text { in } \%\end{array}$} & \multicolumn{4}{|c|}{$\begin{array}{l}\text { Prozentgehalt an Stickstoff, der nach } \\
\text { Bun sen in Harnstoff enthalten ist, } \\
\text { berechnet } \\
\text { für den nicht aus- für den ausge- } \\
\text { gefällten Harn aus: fällten Harn aus: }\end{array}$} & \multirow[t]{2}{*}{$\begin{array}{l}\text { Fehler } \\
\text { der } \\
\text { Methode } \\
\text { von } \\
\text { Bunsen }\end{array}$} & \multirow{2}{*}{$\begin{array}{l}\text { Wie viel } \\
\text { Stickstoff } \\
\text { nicht in } \\
\text { Harnstoff, } \\
\text { wenn Ge- } \\
\text { sammtstick- } \\
\text { stoff }=100\end{array}$} \\
\hline & & $\mathrm{NH}_{3}$ & $\mathrm{CO}_{2}$ & $\mathrm{NH}_{3}$ & $\mathrm{CO}_{2}$ & & \\
\hline 1 & 0,588 & 0,556 & 0,544 & 0,544 & 0,531 & $+2,4$ & $9,7 \%$ \\
\hline 2 & 1,189 & & & 1,058 & 1,017 & & 15,9 \\
\hline 3 & 1,148 & 1,063 & 1,090 & 1,017 & 0,988 & $+9,4$ & 13,8, \\
\hline 4 & 1,178 & 1,120 & 1,131 & 1,060 & 1,038 & $+8,96$ & 11,9 \\
\hline 5 & 1,568 & 1,464 & 1,473 & 1,369 & 1,332 & $+10,6$ & 15,0 \\
\hline 6 & 0,989 & 0,936 & 0,948 & 0,885 & 0,851 & $+11,3$ & 13,9 \\
\hline 7 & 0,676 & 0,627 & 0,617 & 0,609 & 0,603 & $+2,3$ & 10,8, \\
\hline \multirow[t]{2}{*}{8} & 1,3996 & 1,313 & 1,290 & 1,220 & 1,176 & $+9,7$ & 16,0 \\
\hline & \multicolumn{4}{|c|}{ Mittel $=0,9703$} & 0,9440 & $+7,8$ & $13,4^{0} / 0$ \\
\hline
\end{tabular}

Unsere Untersuchung hat somit ergeben, dass die Methode von $\mathrm{Bunsen}$ bei manchen an gewissen Extractivstoffen ärmeren Harnen einen mässigen Beobachtungsfehler von 2 bis $3 \%$ anfweist. Die Regel ist das aber nicht. Gewöhnlich ist der Febler viel mal grösser und erreicht $11 \%$ und mehr.

Durch die Verbesserung der Methode von Bunsen sind wir zu der wichtigen Entdeckung geführt worden, dass neben dem Harnstoff sehr viel mehr stickstoffhaltige Substanzen im menschlichen Harne vorkommen, als man bisher wusste. Im Mittel sind $13,4 \%$ des gesammten im Harn enthaltenen Stickstoffs nicht in Harnstoff gebunden.

Diese Resultate sind offenbar von solcher Wichtigkeit und 
so unerwartet, dass es uns geboten schien, dieselben noch auf einem andern. Wege sicher zu stellen.

Ein Reagens zur Fällung vieler „Extractivstoffe", welches jeden Verdacht ausschliesst, dass doch ein Theil des Harnstoffs mit niedergeschlagen worden sein könne, ist absoluter Alkohol oder ein Gemenge von gleichen Volumina absoluten Aethers und Alkohols. Diese Reagentien leisten in der Elimination der störenden „Extractivstoffe" nicht ganz so viel, wie die Phosphorwolframsäure. Die Versuche genügten aber, um die mit jener Säure gewonnenen wichtigen Resultate als principiell richtig zu erweisen.

\section{Versuchsserie IX. \\ Harn IV.}

I. Gesammtstickstoff.

Je $5 \mathrm{ccm}$ Harn mit $40 \mathrm{ccm}$ rauchender Schwefelsäure 10 Stunden gekocht. Vorlage $60 \mathrm{ccm} 1 / 10 \mathrm{SO}_{4} \mathrm{H}_{2}$.

$1 / 10$ Hyposulfitlösung $=10,9 \mathrm{ccm}: 0,06894 \mathrm{gr}$ Stickstoff. do. $=10,75 \mathrm{~cm}: 0,06915 \mathrm{gr} \quad$ "

Mittel : $0,069045 \mathrm{gr}$ Stickstoff.

Harn enthält 1,3809\% Stickstoff in toto.

II. Harnstoffbestimmung nach Bunsen ohne Elimination der durch Phosphorwolframsäure fällbaren "Extractivstoffe."

1. $32 \mathrm{ccm}$ Harn auf $100 \mathrm{ccm}$ verdünnt; $50 \mathrm{ccm}$ der Mischung mit gleichem Volum alkalischer $\mathrm{Cl}_{2} \mathrm{Ba}$-lösung versetzt; und vom Filtrate je $15 \mathrm{ccm}$ $=2,4 \mathrm{ccm}$ Harn eingeschmolzen. Alkalescenzbestimmung $: 15 \mathrm{ccm}=12,9 \mathrm{~cm}$ $1 / 10$ Alkali.

2. a) Ammoniakbestimmung.

Vorlage $30 \mathrm{~cm} 1 / 10 \mathrm{SO}_{4} \mathrm{H}_{2}$.

Rohr I. Mit MgO destillirt.

$1 / 10$ Hyposulfitlösung $=7,79 \mathrm{~cm}: 0,03118 \mathrm{gr}$ Stickstoff, auf $5 \mathrm{ccm}$ Harn berechnet $=0,06496 \mathrm{gr}$ "

Harn enthält 1,299\% Stickstoff in Harnstoff.

a) Kohlensäurebestimmung.

Rohr II.

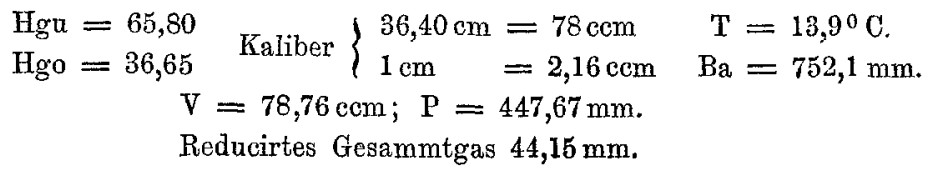


Nach Absorption der Kohlensäure:

$$
\begin{gathered}
\mathrm{Hgu}=66,04 \\
\mathrm{Hgo}=22,60 \text { Kaliber }\left\{\begin{array}{l}
21,05 \mathrm{~cm}=45 \mathrm{~cm} \quad \mathrm{~T}=13,7^{\circ} \mathrm{C} . \\
1 \mathrm{~cm}=2,14 \mathrm{~cm} \mathrm{Ba}=753, \mathrm{~mm} .
\end{array}\right. \\
\text { K0H }=21,65 \\
\nabla=46,28 \mathrm{~cm} ; \mathrm{P}=311,99 \mathrm{~mm} . \\
\text { Reducirtes restirendes Gas }=18,09 \mathrm{~cm} .
\end{gathered}
$$

Folglich: $26,06 \mathrm{ccm} \quad \mathrm{CO}_{2}=51,25 \mathrm{mgr} \quad \mathrm{CO}_{2}=69,88 \mathrm{mgr} \stackrel{+}{\mathrm{U}}$ $=0,03261 \mathrm{gr}$ Stickstoff.

Für $5 \mathrm{ccm}$ IIarn berechnet $=0,06794 \mathrm{gr}$ Stickstoff.

Der Harn enthält 1,359\% Stickstoff in Harnstoff.

III. Harnstoffbestimmung nach Bunsen nach Elimination der durch Phosphorwolframsäure fällbaren "Extractivstoffe."

1.

$$
\begin{aligned}
& 200,3 \mathrm{ccm} \text { Harn, } \\
& 20,0 \text { " Salzsäure, } \\
& 120,0 \text { Phosphorwolframsäure, } \\
& \text { 340,3 ccm Mischung. }
\end{aligned}
$$

Volum des entstandenen Niederschlages $=1,5 \mathrm{ccm}$, vom sauren Filtrat $200,3 \mathrm{ccm}=118,42 \mathrm{ccm}$ Harn abgemessen und mit Kalkpulver $\left(\mathrm{Ca}(\mathrm{OH})_{2}\right)$ alkalisch gemacht und filtrirt; dann mit gleichem Volum alkalischer $\mathrm{Cl}_{2} \mathrm{Ba}$-lösung versetzt und vom Filtrat je $15 \mathrm{ccm}$ eingeschmolzen.

Die Expansion bei Ausfällung mlt $\left(\mathrm{Ca}(\mathrm{OH})_{2}\right.$ betrug $=4,5 \mathrm{ccm}$, das Volum des entstandenen Niederschlages $=2,83$ "

$$
\text { folglich Plus an Expansion }=1,67 \text { " }
$$

$15 \mathrm{ccm}$ der alkalischen $\mathrm{Cl}_{2}$ Ba-Harnmischung $=4,397 \mathrm{~cm}$ Harn.

2. a) Ammoniakbestimmung.

Vorlage $50 \mathrm{ccm} 1 / 10 \mathrm{SO}_{4} \mathrm{H}_{2}$.

Rohr I. Mit MgO destillirt.

1/10 Hyposulfitlösung $=11,53 \mathrm{ccm}: 0,05401 \mathrm{gr}$ Stickstoff, auf $5 \mathrm{~cm}$ Harn berechnet $=0,06142 \mathrm{gr} \quad$ "

Harn enthält 1,228\% Stickstoff in Harnstoff.

b) Kohlensäurebestimmung.

Rohr II.

$$
\begin{aligned}
& \begin{aligned}
\mathrm{Hgu}=65,85 \\
\mathrm{Hgo}=40,29
\end{aligned} \quad \text { Kaliber }\left\{\begin{array}{l}
40,50 \mathrm{~cm}=87 \mathrm{~cm} \quad \mathrm{~T}=14,0^{\circ} \mathrm{C} . \\
1 \mathrm{~cm}=2,22 \mathrm{ccm} \quad \mathrm{Ba}=747,9 \mathrm{~mm} .
\end{array}\right. \\
& \mathrm{V}=86,75 \mathrm{~cm} ; \mathrm{P}=479,21 \mathrm{~mm} \text {. } \\
& \text { Reducirtes Gesammtgas }=52,03 \mathrm{ccm} \text {. }
\end{aligned}
$$

Nach Absorption der Kohlensäure:

$$
\begin{aligned}
& \mathrm{Hgu}=66,20
\end{aligned}
$$

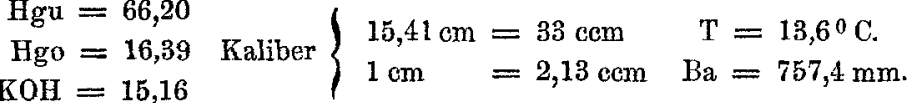

$$
\begin{aligned}
& \mathrm{V}=32,47 \mathrm{ccm} ; \mathrm{P}=252,59 \mathrm{~mm} \text {. } \\
& \text { Reducirtes restirendes Gas }=10,28 \mathrm{~cm} \text {. }
\end{aligned}
$$


Folglich: $41,75 \mathrm{ccm} \mathrm{CO}_{2}=82,106 \mathrm{mgr} \quad \mathrm{CO}_{2}=111,96 \mathrm{mgr} \stackrel{+}{\mathrm{U}}$ $=0,05225 \mathrm{gr}$ Stickstoff.

Rohr III.

$$
\begin{gathered}
\text { Hgu }=64,42 \\
\text { Hgo }=40,12 \quad \text { Kaliber }\left\{\begin{array}{l}
40,95 \mathrm{~cm}=87 \mathrm{~cm} \quad \mathrm{~T}=14,0^{\circ} \mathrm{C} . \\
1 \mathrm{~cm}=2,14 \mathrm{ccm} \quad \mathrm{Ba}=747,9 \mathrm{~mm} . \\
\mathrm{V}=85,44 \mathrm{ccm} ; \mathrm{P}=491,78 \mathrm{~mm} .
\end{array}\right. \\
\text { Reducirtes Gesammtgas }=52,59 \mathrm{~cm} .
\end{gathered}
$$

Nach Absorption der Kohlensäure:

$$
\begin{gathered}
\mathrm{Hga}=64,80 \\
\mathrm{Hgo}=16,28 \text { Kaliber }\left\{\begin{array}{l}
15,55 \mathrm{~cm}=33 \mathrm{~cm} \quad \mathrm{~T}=13,6{ }^{\circ} \mathrm{C} . \\
1 \mathrm{~cm}=2,069 \mathrm{~cm} \mathrm{Ba}=757,4 \mathrm{~mm} .
\end{array}\right. \\
\mathrm{KOH}=15,03 \\
\mathrm{~V}=31,92 \mathrm{ccm} ; \mathrm{P}=265,44 \mathrm{~mm} . \\
\text { Reducirtes restirendes Gas }=10,62 \mathrm{ccm} .
\end{gathered}
$$

Folglich: $41,97 \mathrm{~cm} \mathrm{CO}_{2}=82,54 \mathrm{mgr} \quad \mathrm{CO}_{2}=112,56 \mathrm{mgr} \stackrel{+}{\mathrm{U}}$

$$
\begin{aligned}
& =0,05252 \mathrm{gr} \text { Stickstoff. } \\
\text { Mittel } & =0,05238 \mathrm{gr} \quad "
\end{aligned}
$$

auf $5 \mathrm{com}$ Harn berechnet $=0,05957 \mathrm{gr} \quad$ "

Harn enthält $1,1914 \%$ Stickstoff in Harnstoff.

IV. Harnstoffbestimmug nach Bunsen a ach Elimination der durch Aether-Alkohol fällbaren "Extractivstoffe."

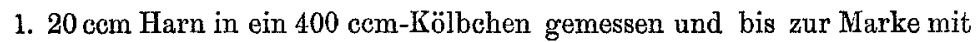
einer Mischung ausgleichen Volumina wasserfreien Alkohols und wasserfreien Aethers bis zur Marke aufgefüllt, und über Nacht stehen gelassen; dann abfiltrirt in ein $400 \mathrm{~cm}$ Kölbchen und aus einer Bürette 8,2 ccm der Alkoholund Aethermischung zugesetzt, so dass abermals $400 \mathrm{ccm}$ Flüssigkeit. Nun in einen Kolben gegossen, ausgespült und im Exsiccator an der Strahlpumpe verdunstet, dann bei Zimmertemperatur im absolut trocknen Vaccum (Quecksilberpumpe) getrocknet; der Trockenrückstand mit $60 \mathrm{ccm}$ Wasser aufgenommen, gleiches Volum alkalischer $\mathrm{Cl}_{2} \mathrm{Ba}$-lösung zugesetzt, filtrirt und je $15 \mathrm{ccm}=2,449 \mathrm{~cm}$ Harn eingeschmolzen.

2. a) Ammoniakbestimmung:

Vorlage $25 \mathrm{ccm} 1 / 10 \quad \mathrm{SO}_{4} \mathrm{H}_{2}$.

Rohr I. Mit MgO destillirt.

$1 / 10$ Hyposulfitlösung $=2,84 \mathrm{ccm}: 0,03111 \mathrm{gr}$ Stickstoff, auf $5 \mathrm{ccm}$ Harn berechnet $=0,06354 \mathrm{gr} \quad "$

Harn enthält also $1,2708 \%$ Stickstoff in Harnstoff.

b) Kohlensäurebestimmung:

Rohr II.

$$
\begin{gathered}
\text { Hgu }=65,61 \quad \text { Kaliber }\left\{\begin{array}{l}
35,00 \mathrm{~cm}=75 \mathrm{~cm} \quad \mathrm{~T}=14,1^{\circ} \mathrm{C} . \\
1 \mathrm{~cm}=2,14 \mathrm{~cm} \quad \mathrm{Ba}=762,8 \mathrm{~mm}
\end{array}\right. \\
\text { Hgo }=35,81 \quad \mathrm{~V}=76,95 \mathrm{~cm} ; \mathrm{P}=451,62 \mathrm{~mm} . \\
\text { Reducirtes Gesammtgas }=43,48 \mathrm{~cm} .
\end{gathered}
$$


Nach Absorption der Kohlensäure:

$$
\begin{aligned}
& \begin{aligned}
\mathrm{Hgu} & =65,81 \\
\mathrm{Hgo} & =23,11 \\
\mathrm{KOH} & =21,90
\end{aligned} \quad \text { Kaliber }\left\{\begin{array}{l}
21,05 \mathrm{~cm}=45 \mathrm{~cm} \quad \mathrm{~T}=14,2^{\circ} \mathrm{C} . \\
1 \mathrm{ccm}=2,14 \mathrm{ccm} \quad \mathrm{Ba}=762,8 \mathrm{~mm} .
\end{array}\right. \\
& \mathrm{V}=46,82 \mathrm{~cm} ; \quad \mathrm{P}=328,71 \mathrm{~mm} \text {. } \\
& \text { Reducirtes restirendes Gas }=19,25 \mathrm{ccm} \text {. }
\end{aligned}
$$

Folglich: $24,24 \mathrm{~cm} \mathrm{CO} \mathrm{CO}_{2}=47,65 \mathrm{mgr} \mathrm{CO}_{2}=64,96 \mathrm{mgr} \stackrel{+}{\mathrm{U}}$

Rohr II.

$$
=0,03032 \mathrm{gr} \text { Stickstoff. }
$$

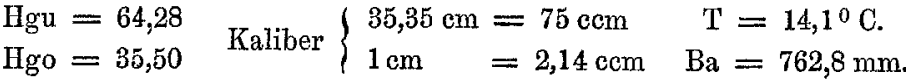

$$
\begin{aligned}
& \mathrm{V}=75,535 \mathrm{cem} ; \mathrm{P}=461,86 \mathrm{~mm} \text {. } \\
& \text { Reducirtes Gesammtgas }=43,65 \mathrm{ccm} \text {. }
\end{aligned}
$$

Nach Absorption der Kohlensäure:

$$
\begin{aligned}
\text { Hgu } & =64,48 \\
\mathrm{Hgo} & =22,97 \\
\mathrm{KOH} & =21,70 \\
\mathrm{~V} & =45,90 \mathrm{ccm} ; \mathrm{P}=340,51 \mathrm{~mm} .
\end{aligned} \quad \text { Kaliber }\left\{\begin{array}{l}
22,70 \mathrm{~cm}=48 \mathrm{~cm} \\
1 \mathrm{~cm}=14,2^{\circ} \mathrm{C} .
\end{array}\right.
$$

Reducirtes restirendes Gas $=19,55 \mathrm{ccm}$.

Folglich: $24,10 \mathrm{ccm} \mathrm{CO}_{2}=47,395 \mathrm{mgr} \mathrm{CO}_{2}=64,63 \mathrm{mgr} \stackrel{+}{\mathrm{U}}$

$$
=0,03016 \mathrm{gr} \text { Stickstoff. }
$$

$$
\text { Mittel }=0,03024 \mathrm{gr} \quad n
$$

auf $5 \mathrm{ccm}$ Harn berechnet $=0,06174 \mathrm{gr} \quad$ "

Der Harn enthält also $1,235 \%$ Stickstoff in Harnstoff.

V. Harnstoffbestimmung nach Bunsen nach Elimination der durch Alkohol fällbaren Extractivstoffe.

1. $20 \mathrm{ccm}$ Harn in ein $400 \mathrm{ccm}-K o ̈ l b c h e n$ gemessen und mit wasserfreiem Alkohol bis zur Marke aufgefüllt, über Nacht stehen gelassen; dann in ein $400 \mathrm{ccm}-K o ̈ l b c h e n$ abfiltrirt und aus einer Bürette $6,32 \mathrm{ccm}$ wasserfreien Alkohols zugesetzt, so dass wieder $400 \mathrm{~cm}$ Flüssigkeit; jetzt in einen grösseren Kolben gegossen und in diesen nachgespült, im Exiccator an der Strahlpumpe verdunstet und im absolut trockenen Vacuum der Quecksilberpumpe bei Zimmertemperatur getrocknet; der Trockenrïckstand mit $60 \mathrm{cem}$ Wasser aufgenommen, ein gleiches Volum alkalischer $\mathrm{Cl}_{2} \mathrm{Ba}-$ lösung zugesetzt, filtrirt und je $15 \mathrm{ccm}=2,461 \mathrm{ccm}$ Harn eingeschmolzen.

2. a) Ammoniakbestimmung.

Vorlage $25 \mathrm{ccm} 1 / 10 \quad \mathrm{SO}_{4} \mathrm{H}_{2}$.

Rohr I. Mit MgO destillirt.

$1 / 10$ Hyposulfitlösung $=2,80 \mathrm{ccm}: 0,03117 \mathrm{gr}$ Stickstoff, auf $5 \mathrm{ccm}$ Harn berechnet $=0,06333 \mathrm{gr} \quad$ "

Der Harn enthält also $1,2666 \%$ Stickstoff. 
b) Kohlensänrebestimmung:

Rohr II.

$$
\begin{gathered}
\text { Hgu }=65,60 \quad \text { Kaliber }\left\{\begin{array}{l}
30,85 \mathrm{~cm}=66 \mathrm{~cm} \quad \mathrm{~T}=14,2^{\circ} \mathrm{C} . \\
1 \mathrm{~cm}=2,206 \mathrm{~cm}
\end{array} \quad \mathrm{Ba}=761,6 \mathrm{~mm} .\right. \\
\mathrm{Hgo}=30,50 \quad \mathrm{~V}=65,45 \mathrm{ccm} ; \mathrm{P}=397,55 \mathrm{~mm} . \\
\text { Reducirtes Gesammtgas }=32,55 \mathrm{ccm} .
\end{gathered}
$$

Nach Absorption der Kohlensäure:

$$
\begin{aligned}
& \begin{aligned}
\mathrm{Hgu} & =65,83 \\
\mathrm{HgO} & =14,55 \\
\mathrm{KOH} & =13,05
\end{aligned} \text { Kaliber }\left\{\begin{array}{l}
14,00 \mathrm{~cm}=30 \mathrm{ccm} \quad \mathrm{T}=14,2^{\circ} \mathrm{C} . \\
1 \mathrm{~cm}=2,098 \mathrm{~cm} \mathrm{Ba}=761,5 \mathrm{~mm} .
\end{array}\right. \\
& \mathrm{V}=28,01 \mathrm{~cm} ; \mathrm{P}=241,52 \mathrm{~mm} \text {. } \\
& \text { Reducirtes restirendes Gas }=8,46 \mathrm{ccm} \text {. }
\end{aligned}
$$

Folglich: $24,09 \mathrm{~cm} \mathrm{CO}_{2}=47,376 \mathrm{mgr} \mathrm{CO}_{2}=64,60 \mathrm{mgr} \stackrel{+}{\mathrm{U}}$ $=0,03015 \mathrm{gr}$ Stickstoff.

Rohr III.

$$
\begin{gathered}
\text { Hgu }=64,23 \quad \text { Kaliber }\left\{\begin{array}{l}
36,75 \mathrm{~cm}=78 \mathrm{ccm} \\
1 \mathrm{~cm}=2,14 \mathrm{~cm}
\end{array} \quad \mathrm{Ta}=14,2^{\circ} \mathrm{C} .\right. \\
\mathrm{Hgo}=35,75,6 \mathrm{~mm} . \\
\text { Reducirtes Gesammtgas }=46,07 \mathrm{ccm} ; \mathrm{P}=463,59 \mathrm{~mm} .
\end{gathered}
$$

Nach Absorption der Kohlensäure:

$$
\begin{aligned}
& \text { Hgu }=64,45 \\
& \text { Hgo }=23,19 \\
& \mathrm{KOH}=21,85
\end{aligned} \text { Kaliber }\left\{\begin{array}{l}
21,27 \mathrm{~cm}=45 \mathrm{~cm} \quad \mathrm{~T}=14,2^{\circ} \mathrm{C} . \\
1 \mathrm{~cm}=2,098 \mathrm{~cm} \quad \mathrm{Ba}=761,5 \mathrm{~mm} .
\end{array}\right.
$$$$
\text { Reducirtes restirendes Gas }=19,75 \mathrm{ccm} \text {. }
$$

Folglich: $24,36 \mathrm{~cm} \mathrm{CO}_{2}=47,91 \mathrm{mgr} \quad \mathrm{CO}_{2}=65,34 \mathrm{mgr} \stackrel{+}{\mathrm{U}}$

$$
=0,03049 \mathrm{gr} \text { Stickstoff. }
$$

$$
\text { Mittel }=0,03032 \mathrm{gr} \quad,
$$

auf $5 \mathrm{ccm}$ Harn berechnet $=0,06160 \mathrm{gr}$,

Der Harn enthält also: 1,232\% Stickstoff in Harnstoff.

Zwei Bedenken gegen Versuchsserie IX miissen kurz besprochen werden.

Der trockne Rückstand des aetherisch-alkoholischen, resp. des alkoholischen Harnextractes wurde mit $60 \mathrm{ccm}$ Wasser aufgenommen und in der Rechnung vorausgesetzt, dass sich das Volum der Flüssigkeit nicht ausdehne durch Auflösung des Rückstandes. Wir haben desshalb direkt die Grösse des Fehlers untersucht. Der Rïckstand des aetherisch-alkoholischen Extractes von $20 \mathrm{cem}$ des Harns wog $0,9 \mathrm{gr}$ und veranlasste bei der Lösung in Wasser eine Volumzunahme von $0,5 \mathrm{ecm}$. Führt man nun die Rechnung aus, so 


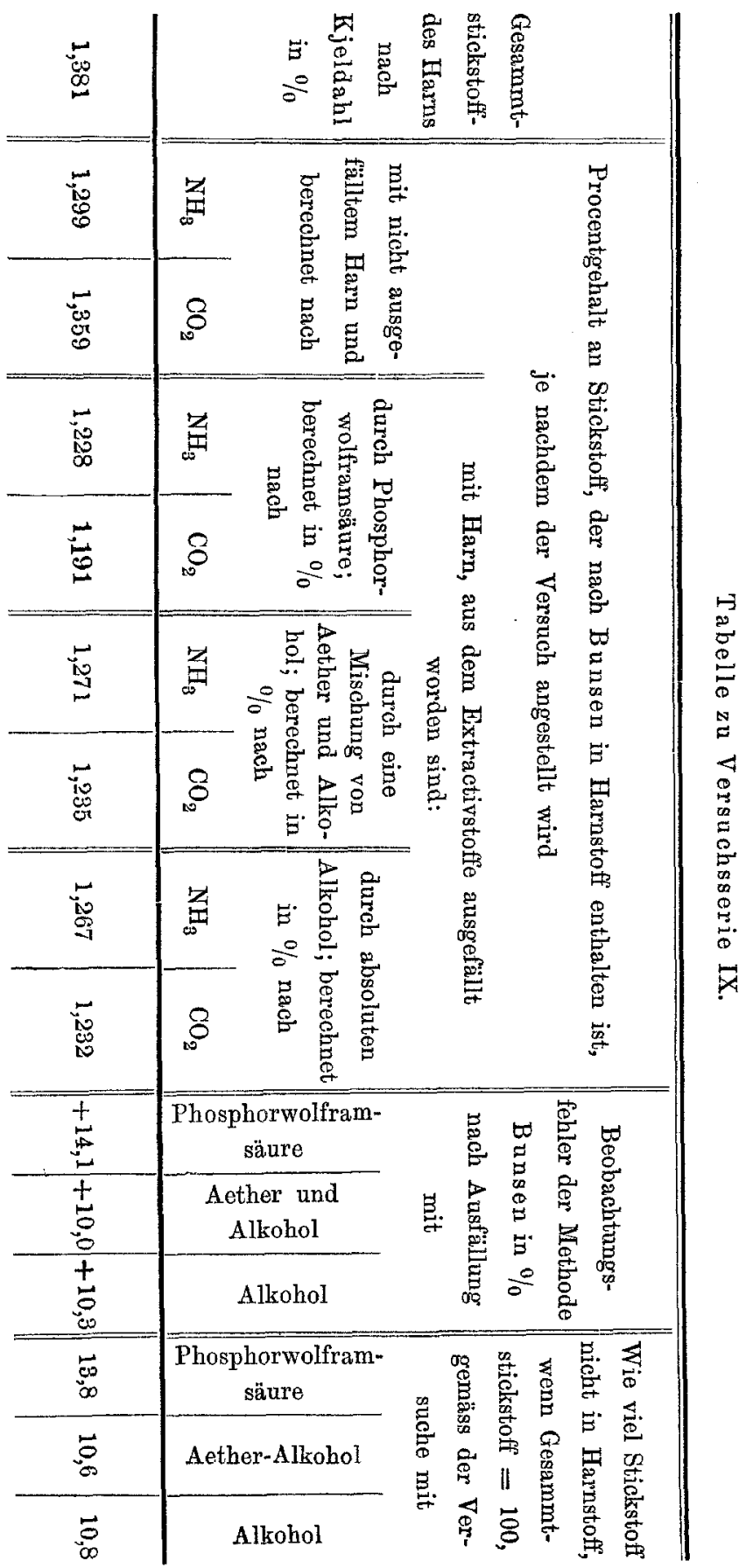


erhält man in $15 \mathrm{cem}$ der eingeschmolzenen Flüssigkeit $2,440 \mathrm{ccm}$ Harn, während die uncorrigirte Rechnung 2,449 ccm Harn ergeben hätte. Die weitere Calculation zeigt, dass die Vernachlässigung der vorliegenden geringen Expansion für den Stickstoff einen Fehler von nur $0,5 \%$ ausmachte, der füglich hier vernachlässigt werden kann.

Das zweite Bedenken ist folgendes: Man könnte behaupten, dass bei der Abdunstung des alkoholisch-aetherischen Extractes der Riuckstand immer wasserreicher werde und deshalb Fermentationen schliesslich nicht mehr ausgeschlossen seien. Sobald der Harnstoff in Folge dessen in kohlensaures Ammoniak übergegangen sei, müsse dieses mit den Dämpfen des Aethers, Alkohols und Wassers entweichen und der Riickstand bei der Analyse nach Bunsen einen geringeren Gehalt an Harnstoff vortäuschen. Wir haben nun aber den Rückstand, nachdem er mit Wasser wieder gelöst worden war, auf seine Reaction geprifit und diese stark saner gefunden. Wenn nun trotzdem ein Theil des Harnstoffs Ammoniumcarbonat gebildet hätte, so würde wegen der Zerlegung desselben durch die vorhandenen Säuren, wohl Kohlensäure aber doch kein Ammoniak haben verloren gehen können. Denn wir dunsteten ja im Vacuum und ohne Erwärmung ab. Was deshalb ein starkes Argument gegen diese Bedenken darstellt, liegt in dem Verhältniss der Kohlensäure zu dem Ammoniak, die bei der Analyse nach $B$ unsen gefunden worden sind. Es ergab sich für den $\%$-Gehalt an in Harnstoff enthaltenem Stickstoff, je nachdem aus Kohlensäure oder Ammoniak berechnet war, für den alkobolisch-aetherischen Extract das Verhältniss $\frac{1235\left(\mathrm{CO}_{2}\right)}{1271\left(\mathrm{NH}_{3}\right)}$, was einer Differenz von 2,9\%, und für den alkoholischen Extract das Verhältniss $\frac{1232\left(\mathrm{CO}_{2}\right)}{1267\left(\mathrm{NH}_{3}\right)}$, was einer Differenz von 2,8\% entspricht.

Ja derselbe Harn ergab nach Ausfällung mit Phosphorwolframsänre das Verhältniss $\frac{1191\left(\mathrm{CO}_{2}\right)}{1228\left(\mathrm{NH}_{3}\right)}$, was abermals einer Differenz von $2,9 \%$ entspricht.

Nun hat die Gesammtheit unserer Versuche, 'in denen wir die Extractivstoffe mit Phosphorwolframsäure ausfällten, ${ }_{, .}^{\infty}$ ganz dieselbe Differenz 2,9\% ergeben. (Siehe die Generaltabelle.)

In Anbetracht der Wichtigkeit der Verhältnisse haben wir 
aber doch noch eine Serie angestellt, ganz so wie die Serie IX, nur mit dem Unterschied, dass dem alkoholisch-aetherischen Extract von cirea $20 \mathrm{ccm}$ Harn schon vor dem Verdunsten $1 \mathrm{gr}$ Phenol zugefuigt wurde, das sicher alle Fermentation ausschliesst.

\section{Versuchsserie $\mathrm{X}$.}

\section{Harn III.}

\section{Gesammtstickstoff.}

Nach Kjeldahl je $5 \mathrm{ccm}$ Harn 10 Stunden mit $40 \mathrm{ccm}$ rauchender Schwefelsäure gekocht. Vorlage $45 \mathrm{ccm} \mathrm{1/10} \mathrm{SO}_{4} \mathrm{H}_{2}$.

Gebraucht 1/10 Hyposulfitlösung: $9,36 \mathrm{ccm}$ und $9,41 \mathrm{ccm}$, entsprechend: $0,05004 \mathrm{gr}, 0,04997 \mathrm{gr}$ Stickstoff.

Demnach enthält der Harn 1,00\% Stickstoff in toto.

II. Harnstoffanalyse nach Bunsen ohne Ausfällung der

$$
\text { Extractivst offe。 }
$$

1. $45 \mathrm{ccm}$ Harn auf $100 \mathrm{ccm}$ verdünnt; mit gleichem Volum alkalischer $\mathrm{BaCl}_{2}$-Lösung versetzt. $15 \mathrm{ccm}$ alkalischer Mischung also $=3,375 \mathrm{ccm}$ Harn.

2. a) Rohr I. Ammoniakbestimmung.

Mit $\mathrm{MgO}$ destillirt. Vorlage $30 \mathrm{ccm} 1 / 10 \mathrm{SO}_{4} \mathrm{H}_{2}$.

Gebraucht 1/10 Hyposulfitlösung 7,26:0,03193 gr Stiekstoff.

5 ccm Harn: $0,0473 \mathrm{gr}$ Stickstoff.

Harn enthält also $0,946 \%$ Stickstoff in Harnstoff.

b) Kohlensäurebestimmung.

Rohr II.

$$
\begin{gathered}
\text { Hgu }=66,17 \quad \text { Kaliber }\left\{\begin{array}{l}
39,15 \mathrm{~cm}=84 \mathrm{~cm} . \quad \mathrm{c}=12,4^{0} \mathrm{C} . \\
1 \mathrm{~cm}=2,22 \mathrm{ccm} \quad \mathrm{Ba}=754,2 \mathrm{~mm} . \\
\mathrm{Hgo}=39,28 \quad \mathrm{~m}=84,51 \mathrm{ccm} ; \mathrm{P}=473,54 \mathrm{~mm} .
\end{array}\right. \\
\text { Reducirtes Gesammtgas }=50,371 \mathrm{ccm} .
\end{gathered}
$$

Nach Absorption der Kohlensäure:

$$
\begin{aligned}
& \mathrm{Hgu}=66,25 \\
& \mathrm{Hgo}=27,15 \\
& \mathrm{KOH}=25,90 \\
& \mathrm{~V}=55,391 \mathrm{ccm} ; \quad \mathrm{P}=352,18 \mathrm{~mm} \text {. } \\
& \text { Reducirtes restirendes Gas }=24,417 \mathrm{ccm} \text {. } \\
& \text { Folglich } 25,954 \mathrm{ccm} \mathrm{CO} \mathrm{CO}_{2}=51,04 \mathrm{mgr} \mathrm{CO}_{2}=69,60 \mathrm{mgr} \stackrel{+}{\mathrm{U}} \\
& =0,03248 \mathrm{gr} \text { Stickstoff. } \\
& 5 \mathrm{ccm} \text { Harn }=0,0481 \text { " " }
\end{aligned}
$$


III. Harnstoffanalyse nach Bunsen mit dem Harne, nachdem durch Phosphorwolframsäure die "Extractivstoffe" angefällt wurden.

1)

$$
\begin{aligned}
& 200,38 \mathrm{ccm} \text { Harn } \\
& 20,00 " \text { Salzsäure } \\
& 80,00 " \text { Phosphorwolframsäure } \\
& 300,38 \mathrm{ccm} \text { Mischung. }
\end{aligned}
$$

Der Niederschlag hat das Volum von $0,82 \mathrm{ccm}$. - In $200,1 \mathrm{ccm}$ Filtrat sind also $133,85 \mathrm{ccm}$ Harn.

Der Kalkniederschlag . . . . . . . . . . $=0,4$ f für $30 \mathrm{ccm}$

Die Expansion bei Neutralisation mit Kalkwasser $=0,33\}$ Filtrat.

Also Contraction . . . . . . . . . . . . $=0,07$

Dies macht für $200,1 \mathrm{ccm}$ Filtrat $0,466 \mathrm{ccm}$ Contraction.

In $15 \mathrm{ccm}$ der alkalischen $\mathrm{Cl}_{2} \mathrm{Ba}-\mathrm{Harnmischung}$ müssen also sein $5,0286 \mathrm{ccm}$ Harn.

2. a) Rohr I. Ammoniakbestimmung.

Vorlage $35 \mathrm{ccm} 1 / 10 \quad \mathrm{SO}_{4} \mathrm{H}_{2}$.

Gebraucht 1/10 Hyposulfitlösung $=2,93: 0,04503$ gr Stickstoff.

Harn enthält $0,895 \%$ Stickstoff in Harnstoff.

b) Rohr II. Kohlensäurebestimmung.

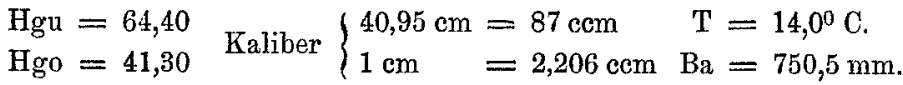

$$
\begin{aligned}
& \mathrm{V}=87,993 \mathrm{ccm} ; \quad \mathrm{P}=506,34 \mathrm{~mm} \text {. } \\
& \text { Reducirtes Gesammtgas }=55,767 \mathrm{ccm} \text {. }
\end{aligned}
$$

Nach Absorption der Kohlensäure:

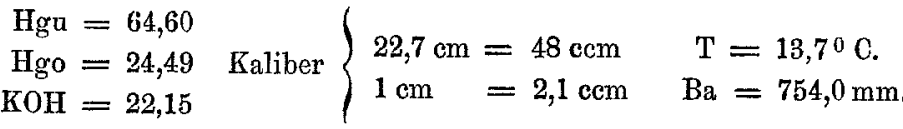

$$
\begin{aligned}
& \mathrm{V}=46,845 \mathrm{ccm} ; \mathrm{P}=344,82 \mathrm{~mm} \text {. } \\
& \text { Reducirtes restirendes Gas }=20,239 \mathrm{ccm} \text {. }
\end{aligned}
$$

Folglich: $35,528 \mathrm{ccm} \mathrm{CO}_{2}=69,87 \mathrm{mgr} \mathrm{CO}_{2}=95,28 \mathrm{mgr} \stackrel{+}{\mathrm{U}}$ entsprechend $0,04445 \mathrm{gr}$ Stickstoff.

$$
5 \mathrm{ccm} \text { Harn }=0,0442 \mathrm{gr} \quad \text { }
$$

Der Harn enthält also 0,884 \% Stickstoff in Harnstoff.

IV. Harnstoffanalyse nach Bunsen in dem Harne, nachdem durch eine Mischung von gleichen Volumina wasserfeien Alkohols und wasserfreien Aethers die Extractivstoffe ausgefällt worden sind.

1. $20 \mathrm{ccm}$ Harm in einen $400 \mathrm{ccm}-$ Kolben. Zusatz der Mischung von gleichen Volumina Aether und Alkohol bis zur Marke. 24 Stunden stehen lassen. Filtration in ein anderes $400 \mathrm{ccm}-K o ̈ l b c h e n$. Es sind noch $9,8 \mathrm{ccm}$ Aether-Alkohol-Zusatz nöthig in das Kölbchen, um wieder $400 \mathrm{ccm}=19,51 \mathrm{ccm}$ 
Harn zu haben. Nun wird in einen grösseren Kolben ausgegossen, nachgespült mit Aether-Alkohol und $1 \mathrm{gr}$ Phenol auch noch der Flüssigkeit zugefügt. Nach der Verdunstung in Vacuo und Trocknung: Aufnahme des Rückstandes mit $45 \mathrm{ccm}$ Wasser. Nach Lösung: Zusatz von $45 \mathrm{ccm}$ der alkalischen $\mathrm{BaCl}_{2}$ lösung. Da der Rückstand und das Phenol eine Expansion von $1,5 \mathrm{ccm}$ bedingten, hat man also $91,5 \mathrm{ccm}$ alkalische Mischung $=19,51 \mathrm{ccm}$ Harn. Darauf je $15 \mathrm{ccm}$ der alkalischen Mischung $=3,1984 \mathrm{ccm}$ Harn in zugeschmolzenen Röhren auf $220^{\circ}$ bis $230^{\circ}$ C. 4 Stunden erhitzt.

Kohlensäurebestimmung:

$$
\begin{gathered}
\mathrm{Hgu}=64,55 \quad \text { Kaliber }\left\{\begin{array}{l}
33,98 \mathrm{~cm}=72 \mathrm{~cm} \quad \mathrm{~T}=17,8^{\circ} \mathrm{C} . \\
1 \mathrm{~cm}=2,19 \mathrm{~cm} \quad \mathrm{Ba}=752,1 \mathrm{~mm} . \\
\mathrm{Hgo}=34,90 \quad \mathrm{P}=74,234 \mathrm{~cm} ; \mathrm{P}=439,05 \mathrm{~mm} .
\end{array}\right. \\
\text { Reducirtes Gesammtgas }=40,262 \mathrm{ccm} .
\end{gathered}
$$

Nach Absorption der Kohlensäure:

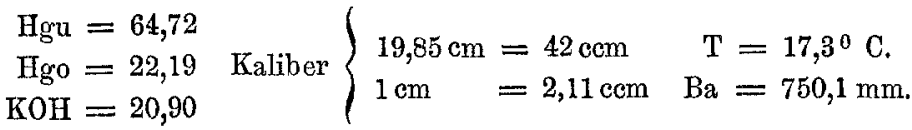

$$
\begin{aligned}
& \mathrm{V}=44,216 \mathrm{ccm} ; \quad \mathrm{P}=316,37 \mathrm{~mm} \text {. } \\
& \text { Reducirtes restirendes Gas }=17,31 \mathrm{ccm} \text {. }
\end{aligned}
$$

Folglich : $22,952 \mathrm{ccm} \mathrm{CO} \mathrm{CO}_{2}=45,188 \mathrm{mgr} \mathrm{CO}_{2}=61,551 \mathrm{mgr} \stackrel{+}{\mathrm{U}}$

$$
\begin{aligned}
& =0,028724 \mathrm{gr} \text { Stickstoff. } \\
5 \mathrm{ccm} \text { Harn } & =0,04493 \mathrm{gr}, \quad,
\end{aligned}
$$

Harn enthält also $0,898 \%$ Stickstoff in Harnstoff.

V. Harnstoffanalyse nach Bunsen in dem Harne, nachdem durch wasserfreien Alkohol Extractivstoffe ausgefällt

$$
\text { worden sind. }
$$

1. $20 \mathrm{ccm}$ Harn in einem $400 \mathrm{ccm}-K o l b e n$ mit Alkohol zu $400 \mathrm{ccm}$ verdünnt; nach 24 Stunden in einen zweiten $400 \mathrm{ccm}$-Kolben $393 \mathrm{ccm}$ filtrirt und $7 \mathrm{ccm}$ Alkohol zugefügt. Diese $400 \mathrm{~cm}$ enthalten also jetzt $19,65 \mathrm{~cm}$ Harn. Im Uebrigen wurde genau so verfahren wie vorher bei IV. 1. Die durch Lösung des Rückstandes und des Phenols bedingte Expansion betrug 1,5 ccm; also $91,5 \mathrm{ccm}$ alkalische $\mathrm{Cl}_{2}$-Baryumharnmischung $=3,2213 \mathrm{ccm}$ Harn.

Kohlensäurebestimmung:

$$
\begin{aligned}
& \begin{array}{l}
\text { Hgu }=65,41 \\
\text { Hgo }=34,90
\end{array} \quad \text { Kaliber }\left\{\begin{array}{lr}
35 \mathrm{~cm}=75 \mathrm{~cm} & \mathrm{~T}=17,8^{\circ} \mathrm{C} . \\
1 \mathrm{~cm}={ }^{2} 2,14 \mathrm{ccm} & \mathrm{Ba}=752,1 \mathrm{~mm} .
\end{array}\right. \\
& \mathrm{V}=75 \mathrm{ccm} ; \mathrm{P}=430,48 \mathrm{~mm} \text {. } \\
& \text { Reducirtes Gesammtgas }=39,883 \mathrm{ccm} \text {. } \\
& \text { Nach Absorption der Kohlensäure: } \\
& \begin{array}{c}
\mathrm{Hgu}=65,60 \\
\mathrm{Hgo}=21,65 \text { Kaliber }\left\{\begin{array}{l}
19,64 \mathrm{~cm}=42 \mathrm{~cm} \quad \mathrm{~T}=17,3^{\circ} \mathrm{C} . \\
1 \mathrm{~cm}=2,128 \mathrm{ccm} \quad \mathrm{Ba}=750,1 \mathrm{~mm} .
\end{array}\right. \\
\mathrm{KOH}=20,23
\end{array}
\end{aligned}
$$


Folglich: $23,713 \mathrm{ccm} \quad \mathrm{CO}_{2}=46,634 \mathrm{mgr} \mathrm{CO} \mathrm{CO}_{2}=63,591 \mathrm{mgr} \stackrel{+}{\mathrm{U}}$ entsprechend $0,02968 \mathrm{gr}$ Stickstoff.

$5 \mathrm{cem}$ Harn $=0,04605 \mathrm{gr} "$

Der Harn enthält also $0,921 \%$ Stickstoff in Harnstoff.

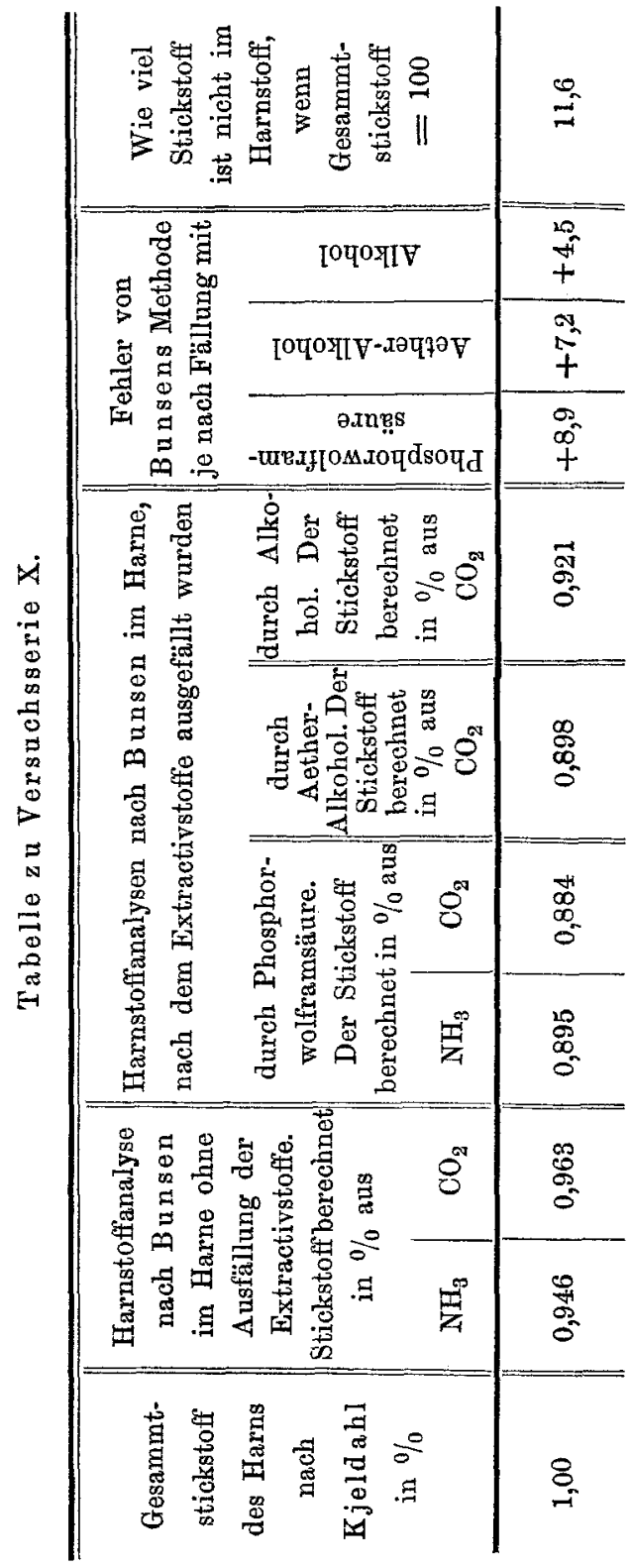

Wiewohl dieser Harn nicht reich an den Extractivstoffen war, welche den Beobachtungsfehler der Bunsen'schen Methode vergrössern, so glauben wir hiermit doch principiell die Richtigkeit der durch Phosphorwolframsäure gewonnenen Ergebnisse bewiesen zu haben.

Da die von uns im zugeschmolzenen Rohr erhitzte Flüssigkeit nicht unbedeutend mehr Stickstoff enthält,als dem durch die Bunsen'sche Analyse gefundenen Harnstoff entspricht, da zweitens das entwickelte Ammoniak sich zu der Kohlensäure nicht genau wie $2 \mathrm{NH}_{3}: 1 \mathrm{CO}_{2}$ verhält, sondern den entsprechenden Werth um im Mittel $2,9 \%$ ausnahmslos übertrifft; da endlich durch die vorliegende Arbeit das Vorkommen nicht unbedeutender Mengen stickstoffhaltiger Substanzen im menschlichen Harne nachgewiesen wurde, 
von denen man bisher nichts wusste, so folgt, dass auch unser Verfahren nur einen Maximalwerth für den Harnstoff liefert, dessen Menge durch fortgesetzte Untersuchungen in Zukunft vielleicht noch weit herabgesetzt werden wird.

Wir möchten uns das Studium dieser Frage, sowie die Erforschung der von uns aufgefundenen unbekannten stickstoffhaltigen Körper für die nächste Zeit vorbehalten.

Wir stellen endlich die Vorschriften zusammen, nach denen die Analyse auszuführen ist:

Vorab prüfe man die Reagentien: $25 \mathrm{ccm}$ Harnstofflösung $(2$ bis $4 \%$ ig $)+2,5 \mathrm{ccm}$ Salzsäure von 1,124 sp. Gew. $+25 \mathrm{ccm}$ Phosphorwolframsäure in ein Kölbchen abgemessen und den eingeschliffenen hermetisch schliessenden Stöpsel aufgesetzt. Die Mischung muss dauernd klar bleiben.

Hierauf bestimmt man den annähernden Stickstoffgehalt des Harns nach der Methode, welche wir in dem vorhergehenden Aufsatz beschrieben haben. Dies ist nützlich, um die Harnstoffmenge annähernd zu wissen, welche sich in dem eingeschmolzenen Rohre befindet, resp. um die Menge $1 / 10$ Schwefelsäure beurtheilen zu können, welche man am Destillationsapparat vorlegen muss, um das entwickelte Ammoniak zu binden.

Zur Anstellung des Vorversuchs misst man $10 \mathrm{ccm}$ Harn $+1 \mathrm{ccm}$ Salzsäure in ein Becherglas ab und fügt so lange Phosphorwolframsäure zu, bis eine filtrirte Probe bei erneutem Zusatz von Phosphorwolframsäure wenigstens 2 Minuten klar bleibt. Eine später eintretende Trübrng ist nicht zu beachten ${ }^{1}$ ).

1) Diese nachträgliche Trübung hat ihren Grund einmal in der Langsamkeit, mit der die letzten Mengen des Niederschlags überhaupt sich abscheiden, sowie wohl auch darin, dass im Harne Körper vorkommen, die erst durch höhere Concentration der Säure gefällt werden. Wollte man die Erscheinung der nachträglichen Trübung ganz vermeiden, so müssten so grosse Volumina Phosphorwolframsäure angewandt werden, dass dadurch die Methode in Frage gestellt würde. 
Nunmehr misst man aus einem auf Ausguss gut geaichten Kolben $200 \mathrm{ccm}$ Harn ab, giesst in einen grösseren Kolben aus, fügt $20 \mathrm{ccm}$ Salzsäure von 1,124 sp. Gew., sowie die nach dem Vorversuch berechnete Menge von Phosphorwolframsäure za, verschliesst hermetisch und lässt wenigstens 24 Stunden stehen. Das Volum dieser Mischung erwies sich immer als gleich der Summe der Volumina der Bestandtheile.

Hierauf filtrirt man durch ein trocknes Filter und misst von dem Filtrat in einem gut geaichten Kolben $200 \mathrm{eem}$ ab. Nach vollständigem Abtropfen des Filters misst man das Volum des durch die Phosphorwolframsäure entstandenen Niederschlags nach dem oben pg. 578 angegebenen Verfahren und berechnet daraus die stattgehabte Contraction der Flüssigkeit. Vernachlässigung dieser Operation bedingt einen nur sehr kleinen Fehler.

Jene $200 \mathrm{ccm}$ saures Filtrat werden nun mit Kalkpulver $\left(\mathrm{Ca}(\mathrm{OH})_{2}\right.$ zerrieben, bis dentlich alkalische Reaction auftritt. Dann wird in ein Kölbchen filtrirt.

Es handelt sich nun darum zu wissen, ob durch die Fällungen und Salzbildungen das Volum der Flitssigkeit sich verändert hat. $\mathrm{Zu}$ dem Ende misst man $30 \mathrm{ccm}$ des sauren Filtrats in ein $200 \mathrm{ccm}$ Kölbchen, dann soviel verdünnte Natronlauge, dass die Salzsäure neutralisirt wird und lässt endlich ein genau gekanntes Volum gesättigtes Kalkwasser bis zur Marke einfliessen, um die etwaige Contraction oder Expansion der Mischung zu bestimmen. Selbstrerständlich muss die Temperatur der Flitssigkeit hierbei beachtet werden. Dann filtrirt man den Niederschlag ab und bestimmt nach dem oben pg. 578 beschriebenen Verfahren sein Volum, sodass die Rechnung, um wieviel die Flüssigkeit ihr Volum geändert hat, leicht ausgefiuhrt werden kann. Diese Correcturen sind sehr lästig. Wenn man sie vernachlässigt, begeht man einen im Mittel irrelevanten Fehler ${ }^{1}$ ).

Das durch Kalk alkalische Filtrat wird nun mit alkalischer

1) Um uns hierüber Klarheit zu verschaffen, haben wir von den ersten E. Pfũger, Archiv für Physiologie. Bd, XXXvin. 
624 E. Pflüger und K. Bohland: Verbesserung der Harnstolf-Analyse etc.

Chlorbaryumlösung nach Salkow sky versetzt und im Einzelnen so verfahren, wie dieser Forscher es in seiner Abhandlung über die Harnstoff bildung ${ }^{1}$ ) vorgeschrieben hat. Doch sei hier betont, dass wir die 15 eingeschmolzenen ccm nie mit Pipette, sondern mit Bürette abmaassen, sowie dass wir die Veränderung der Alkalescenz der eingeschmolzenen Flüssigkeit nicht prüften, da alle unsere Röhren in blinden Versuchen, bei denen sie nur destillirtes Wasser enthielten, bald mebr, bald weniger, aber immer beträchtliche Mengen Alkali abgaben, wenn auf 220 bis $230^{\circ} 4$ Stunden erhitzt wurde. Auch die Röhren, welche wir nach Salkowsky's Empfehlung durch Dr. Geissler's Fabrik von Kawalier aus S atzawa kommen liessen, erwiesen sich nicht besser.

Das durch Erhitzen im zugeschmolzenen Rohr gebildete Ammoniak wird mit $\mathrm{MgO}$ oder $\mathrm{NaOH}$ in $1 / 10$ Schwefelsäure destillirt und deren Uebersehuss mit $\mathrm{JK}_{2} \mathrm{JO}_{3} \mathrm{~K}$ and Natriumbyposufit bestimmt, die Kohlensäure durch Auspumpen, wie es oben pg. 581 beschrieben ist.

Da die Kohlensäure für den Harnstoff einen kleineren Werth ergibt als das Ammoniak, so ist dieser der maasgebende. Die Kohlensäureanalyse ist aber höchst mühsam und zeitraubend. Will man einen kleinen Fehler zulassen, so berechnet man den Harnstoff aus dem Ammoniak und zieht von dem erhaltenen Werth $3 \%$ ab.

8 Serien den procentischen Stickstoffgehalt uncorrigirt und corrigirt berechnet und geben die betreffenden Werthe:

corrigirt:

I. Serie $0,531 \% \mathrm{~N}$

II. " $1,017, "$

III. " 0,988 ". "

IV. " 1,038, " "

V. " 1,332 " "

VI. " $0,851 "$,

VII. " 0,603 " "

VIII. " 1,176 " ,

Mittel: $0,942 \% \mathrm{~N}$

1) Hoppe-Seyler, Zeitschr. f. physiol. Chem. IV, p. õ4 (62 etc.) 